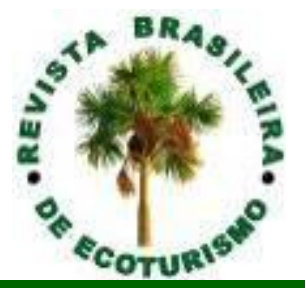

\title{
Geoturismo urbano na Urca: conhecendo o Rio de Janeiro pelo olhar geopoético do Gigante Adormecido
}

\section{Urban Geotourism in Urca: experiencing Rio de Janeiro (Brazil) by the geopoetic view of the Sleeping Giant}

\author{
Bernardo Perrota Legal Gomes, Kátia Leite Mansur, \\ Luiza Corral Martins de Oliveira Ponciano
}

\begin{abstract}
RESUMO:
No Rio de Janeiro, alguns dos destinos turísticos mais famosos da cidade possuem uma intensa conexão com o Patrimônio Geológico. Apesar disso, o potencial para o Geoturismo é pouco desenvolvido pelas atividades turísticas estabelecidas na região. Visando complementar as experiências turísticas oferecidas no Rio de Janeiro, foi elaborado e analisado um novo roteiro para a paisagem da Urca (próximo ao Pão de Açúcar). Integrando as narrativas do Geoturismo com performances artísticas baseadas na Geopoética e na Geomitologia, bem como com informações históricas e socioculturais associadas à evolução urbana do local, nós desenvolvemos uma nova e memorável experiência turística. A incorporação de diferentes áreas do conhecimento (principalmente Geociências, Artes e Museologia) busca promover uma conexão mais ampla entre os visitantes e o Patrimônio Natural, Cultural e Histórico, tendo como objetivo de estimular a Geoconservação e a percepção do Patrimônio de maneira integral. O resultado dessa integração é um roteiro geoturístico estruturado em sete paradas, cada uma delas conectada com a performance de um poema ou conto relacionado com a geodiversidade local. Após as performances são apresentadas as interpretações das características geológicas, geomorfológicas, geográficas, históricas e socioculturais do local, de maneira acessível e lúdica para os visitantes. Testamos esse novo roteiro geoturísticos duas vezes, em junho e novembro de 2018. Os participantes destacaram as performances artísticas dos poemas e contos como o momento mais interessante da atividade, despertando memórias e o vínculo afetivo entre seres humanos e o ambiente. Esta avaliação corrobora a importância da Geopoética e da Geomitologia como um método inovador para despertar o fascínio dos visitantes, abrindo suas mentes para a apresentação subsequente das informações geocientíficas por meio de suas conexões com os sentimentos de pertencimento, germinados pelas Artes.
\end{abstract}

PALAVRAS CHAVE: Ecoturismo; Geoconservação; Geomitologia; Geopoética; Patrimônio Natural. 
ABSTRACT: In Rio de Janeiro, some of the city's most famous tourism destinations have an intense connection with the Geological Heritage. However, the potential for Geotourism is underdeveloped by the usual tourism activities established in the region. In order to complement the tourism experiences offered in Rio de Janeiro, the elaboration and analysis of an inventive new itinerary was carried out in the landscape of Urca (near by the Sugar Loaf). Integrating the Geotourism narratives with artistic performances based on Geopoetics and Geomithology, as well as historical and sociocultural information associated with the urban evolution of the place, we have developed a new memorable tourism experience. The incorporation of different areas (mainly Geosciences, Arts and Museology) seeks to promote a broader connection of the visitors with the Natural, Cultural and Historical Heritage, aiming to stimulate Geoconservation and the perception of the heritage in an integral way. The result is a geotouristic tour structured in seven stops, each one connected with the performance of a poem or tale related to the local geodiversity. After the performances, we introduce the interpretations of the geological, geomorphological, geographical, historical and sociocultural features of the site, in an accessible and playful way to the visitors. We tested this new urban geotouristic tour twice, in June and November of 2018. The visitors highlighted the artistic performances of poems and tales as the most interesting part of the activity, arousing theirs memories of the affective link between humans and the environment. This evaluation corroborates the importance of Geopoetics and Geomithology as an innovative method to fascinate the visitors, opening their minds for the subsequent presentation of the Geosciences information's by their connections with the feelings of belonging, germinated through the Arts.

KEYWORDS: Ecotourism; Geoconservation; Geomithology; Geopoetics; Natural Heritage.

\section{Introdução}

A integração do roteiro geoturístico da Urca com informações históricas e socioculturais associadas à evolução urbana da cidade do Rio de Janeiro e as abordagens artísticas da Geomitologia e da Geopoética possibilitam uma apresentação diferenciada dos conteúdos mais tradicionalmente relacionados ao Geoturismo, abarcando as visões das Geociências, Artes e Geografia. Para entender a importância dessa integração é necessário começar este percurso por uma reflexão sobre como o homem se afastou da Natureza e por que a sua conexão com o ambiente "natural" é algo essencial para a eficiência das práticas de conservação da Natureza. Esse distanciamento se deu ao longo do tempo, à medida que a nossa sociedade foi "controlando" a Natureza para que uma parte de seus membros tivesse uma vida mais confortável. Com o desenvolvimento desse processo de urbanização, fomos nos acostumando a viver afastados dos elementos "naturais" e a nossa percepção sobre eles foi ficando cada vez mais limitada, evitando não só aquilo que pode nos prejudicar ou causar algum tipo de mal-estar, mas também todas as descobertas, o aprendizado e o fascínio que a Natureza pode nos proporcionar (NEIMAN; MENDONÇA, 2000).

Tendo como objetivo nos reaproximar da Natureza e fortalecer as atividades ligadas à sua conservação, surgiram nas últimas décadas uma série de práticas e abordagens que tentavam de alguma forma desenvolver a percepção dessa nossa conexão. Essas atividades visam fortalecer uma relação ética entre os humanos e 
seus ambientes, superando assim práticas de conservação que possuem apenas fins utilitaristas (NEIMAN; MENDONÇA, 2000). Dentro desse contexto, surgem nas décadas de 1980 e 1990 segmentos turísticos que, ao invés de possuir apenas fins comerciais, buscam também o desenvolvimento de atividades que envolvam a conservação da Natureza, das culturas e das comunidades locais. Esse é o caso do Ecoturismo e do segmento que tem o Patrimônio Geológico como seu principal atrativo, o Geoturismo. O objetivo principal desses segmentos é promover um turismo interpretativo, de mínimo impacto e com interesse na conservação do ambiente e das culturas onde suas atividades se realizam (WEARING; NEIL, 2001), trazendo benefícios sociais e econômicos para as populações locais.

Nessa perspectiva, diversos autores destacaram que a eficiência do Ecoturismo e de seus segmentos depende diretamente do envolvimento da população local e da valorização dos aspectos socioculturais dos locais onde as atividades serão realizadas (LINDBERG; HAWKINS, 1995; FERREIRA; COUTINHO, 2002; ARAÚJO, 2003). Seguindo uma linha de pensamento similar, Menéndez (2018) sugere a educação como uma forma de "abrir espaços para a experimentação da própria natureza em relação com as outras naturezas do mundo", considerando natureza "todo o acontecimento do mundo e todo acontecer de cada um". Por meio da observação participante realizada nos projetos "Arte na Terra", "Nosso Quintal" e "Cadernos e Caminhos", além do curso de Introdução em Floresta Escola e na vivência Ecoalfabetização e Educação na Natureza, em Terra Uma, destaca que o poder transformador destas atividades de encontro com a Natureza depende dos afetos, dos sentimentos de pertencimento e dos desejos de conservação e de cuidado que elas podem despertar nas pessoas, sugerindo a experimentação do nosso viver como Natureza acontecendo (MENÉNDEZ, 2018).

O elo afetivo entre as pessoas e os lugares ou ambiente físicos é definido por Tuan (1980) como Topofilia, e a realização deste encontro por meio do Ecoturismo e Geoturismo podem ter como importantes aliadas a Interpretação Ambiental, as Artes e a Geopoética. A Interpretação Ambiental é fundamental para as práticas ecoturísticas, como evidenciado por Wearing e Neil (2001), e pode ser definida como uma ação educativa responsável por revelar significados e relações por meio de objetos e experiências que superem a simples comunicação dos fatos (TILDEN, 1977). Já a integração das atividades ecoturísticas com as manifestações artísticas podem representar experiências de grande valor para a conservação, até mesmo nas áreas urbanas, onde práticas associadas com a conservação da Natureza tendem a ser menos comuns.

Nessa direção, Caprez (2017) ressalta que o sentido da Arte por meio da Geopoética é fazer desabrochar os lugares da cidade, reestabelecendo suas conexões vivenciais, simbólicas e técnicas com as paisagens. Ambas as atividades são, portanto, muito importantes para a conservação, devendo ser aplicadas também em associação com o Geoturismo. Esse é o caso do presente trabalho, focado no desenvolvimento de um roteiro geoturístico urbano que tem como seu principal diferencial a integração entre a geodiversidade presente nas paisagens naturais e culturais do bairro da Urca / Rio de Janeiro (RJ) e as manifestações artísticas e culturais que nelas se inspiraram ou que podem ser utilizadas para facilitar a compreensão e despertar o interesse pela conservação dessas paisagens.

Antes de abordar especificamente o roteiro aqui proposto, é importante relembrar um pouco da história do Geoturismo. O conceito surgiu na década de 
1990, tendo como principal objetivo preencher uma lacuna existente no Ecoturismo, uma vez que essa atividade tem seu maior foco na visitação e compreensão das áreas naturais e de seus aspectos bióticos (NASCIMENTO et al. 2008; MOREIRA, 2014). Sendo assim, na sua vertente mais abrangente, o Geoturismo surge para valorizar e divulgar os aspectos geológicos, geomorfológicos e geográficos de um local. O Geoturismo busca a proteção do patrimônio geológico por meio da sensibilização do turista, utilizando atividades de interpretação para tornar este tipo de patrimônio acessível ao público leigo, promovendo a sua divulgação e o desenvolvimento das Ciências da Terra (GRAY, 2004; RUCHKYS, 2007).

A primeira definição do Geoturismo foi elaborada por Hose (1995), que o definiu como a provisão de serviços e facilidades interpretativas que permitem aos turistas adquirirem conhecimento e entendimento sobre a Geologia e a Geomorfologia de um sítio, extrapolando a mera apreciação estética e incluindo também a contribuição deste para o desenvolvimento das Geociências. Posteriormente, em Hose (2000), o autor atualizou sua definição, ampliando-a para uma abordagem que envolve a provisão de serviços que promovam o valor e os benefícios sociais dos lugares e materiais geológicos e geomorfológicos para o uso de estudantes, turistas e pessoas com interesse recreativo ou de lazer.

No Brasil, outra definição foi elaborada por Ruchkys (2007), que propôs superar a visão reducionista que associa o turismo apenas ao seu caráter econômico. A autora destaca que as atividades turísticas têm uma grande importância para a proteção dos mais variados Patrimônios, que no caso do Geoturismo são representados pelo Patrimônio Geológico. Posteriormente, na Declaração de Arouca (Portugal), elaborada em 2011 sob a coordenação da UNESCO, o conceito de Geoturismo foi definido como o turismo que sustenta e incrementa a identidade de um território, considerando a sua Geologia, seu ambiente, sua cultura, os valores estéticos, bem como o patrimônio e o bem-estar dos residentes.

Apesar do surgimento de várias definições e do crescimento das práticas geoturísticas, a realização dessas atividades em áreas urbanas foi negligenciada por muito tempo. Liccardo et al. (2012, p. 138) afirmam que "a onipresença da Geologia oferece uma argumentação personalizada para cada cidade e a logística facilitada potencializa o Geoturismo urbano, no que tange a educação e a cultura".

Buscando o desenvolvimento de uma abordagem mais integrada e abrangente no Geoturismo, também serão associadas aqui as definições de Patrimônio Natural e de Patrimônio Geológico que envolvem as áreas urbanas e os aspectos culturais e artísticos na realização de roteiros geoturísticos. Será utilizada a definição de Patrimônio Natural de Rêgo e Fernandes (2008), que abrange a Natureza humanizada presente nos elementos e estruturas e na base física e natural sobre as quais as cidades se desenvolvem. Uma abordagem semelhante também pode ser encontrada em Ponciano et al. (2011), que consideram como Patrimônio Geológico tanto os elementos da geodiversidade que permanecem em seu contexto original (in situ),quanto aqueles que foram retirados de seus locais de origem (ex situ) para integrarem coleções científicas de instituições de pesquisas, além dos registros relacionados à sua coleta, guarda e estudo deste material e de outros elementos da geodiversidade, desde que apresentem conspícuo valor científico, didático, cultural, turístico, dentre outros. 
A seleção dessas diferentes abordagens sobre Patrimônio foi necessária tendo em vista o caráter polissêmico deste conceito. Castro et al. (2018), ao discutirem as relações entre Geodiversidade e Patrimônio, destacaram que ao longo do tempo o conceito de Patrimônio assumiu e ainda assume diversos significados, tais como herança, bens (móveis e imóveis) e monumento, que se apresentam como elementos materiais ou imateriais, de acordo com a sociedade em que estão inseridos. O que se define como Patrimônio é sempre um reflexo daquilo que é considerado relevante por uma sociedade e que, portanto, deve ser preservado ou registrado, para que outras pessoas possam contemplar. Portanto, as concepções de Patrimônio de uma sociedade estão sempre relacionadas às suas noções de identidade e pertencimento a um grupo social. Abrem-se assim, possibilidades de práticas de conservação dos patrimônios naturais e geológicos que estejam integradas a aspectos socioculturais que reafirmem as noções de pertencimento dos diferentes grupos sociais, numa percepção do Patrimônio em seu sentido integral (CASTRO et al., 2018).

A conexão de todas essas definições provenientes de diferentes áreas (Geociências, Turismo, Museologia, Artes) fornece uma ampla base teórica e conceitual para a proposição do Roteiro Geoturístico no Bairro da Urca / Rio de Janeiro (RJ). Também foram integradas as análises de Santos (2006) sobre os processos e características que formam o espaço geográfico, conceito chave na Geografia. O bairro da Urca, assim como toda a Cidade do Rio de Janeiro, passou por uma série de modificações em suas estruturas e funções até chegar ao seu estado atual. Esta evolução pode ser vista na combinação de estruturas antigas e novas que compõem a paisagem do bairro, bem como nas diversas funções que estas estruturas ganharam e podem ganhar ao longo dos anos, evidenciando assim o caráter dinâmico do espaço geográfico, associando a visão da Geografia ao roteiro geoturístico.

Desta forma, foram selecionados para serem abordados ao longo do roteiro os seguintes temas: (1) os processos geológicos que levaram à formação dos Morros do Pão de Açúcar e da Urca, além da Baía de Guanabara, destacando-se nesse primeiro tema, os processos de formação e fragmentação do Paleocontinente Gondwana e o metamorfismo que originou o gnaisse facoidal, rocha predominante nos dois morros; (2) as manifestações culturais, como poemas e mitos que estejam relacionados com temas geológicos (Geopoética e Geomitologia), como o Gigante Adormecido; (3) a história e as características que levaram os morros a serem classificados como Monumento Natural, de acordo com o Sistema Nacional de Unidades de Conservação; (4) as mudanças espaciais promovidas pela ação humana no bairro, desde a fundação da cidade até a integração da Urca à expansão urbana da cidade do Rio de Janeiro (na virada do século XIX para o XX); e (5) as características de algumas das construções presentes no bairro, especialmente aquelas que possuem o gnaisse facoidal, como é o caso do Museu de Ciências da Terra.

Todos os tópicos destacados serão desenvolvidos abaixo, reunindo o embasamento teórico utilizado para o planejamento e elaboração do roteiro, junto com a análise das aplicações já realizadas com estudantes de Ensino Médio (prévestibular) e discentes do curso de Museologia da Universidade Federal do Estado do Rio de Janeiro (UNIRIO). Por fim, é importante destacar que o roteiro proposto tem como objetivo utilizar as características naturais e urbanísticas da Urca para evidenciar a relação direta entre a evolução urbana da cidade, suas manifestações 
culturais e suas características geológicas. Visamos assim, por meio da interpretação das informações geológicas, geomorfológicas, geográficas associadas com as performances Geopoéticas apresentadas ao longo do roteiro, contribuir para a conservação, valorização e divulgação do Patrimônio de uma forma integral.

\section{O gigante adormecido e a Geomitologia carioca}

Conforme destacamos acima, as referências sobre Geoturismo são enfáticas em afirmar a importância do envolvimento da população e a necessidade de recuperar a ligação afetiva do homem com o seu ambiente. No caso dos elementos abióticos da paisagem, abordados pelas Geociências, esse envolvimento da população esbarra nas dificuldades de divulgação dos seus conceitos, pelos seus termos não serem muito conhecidos pelo público. Os estudos geocientíficos abrangem diversos temas, tais como a evolução geológica da Terra, suas rochas, formas e processos naturais, além da relação destes com as atividades humanas. Contudo, apesar da sua importância, muitos desses estudos acabam restritos aos trabalhos técnicos e discussões acadêmicas, representando também um problema para a difusão de práticas como o Geoturismo.

Dentre os trabalhos que abordam esta temática podemos citar Mansur (2009), onde a autora aponta que, apesar de não verem perspectiva de entendimento dos temas científicos por parte da população, diversos autores concordam que é fundamental que não se faça concessão ao rigor de tais conceitos. Ela ressalta também o importante papel das diferentes formas de divulgação científica, que tem como objetivo transmitir os conteúdos científicos por meio da decodificação de termos pouco usuais, e que nas Geociências tem como uma das suas principais ferramentas o Geoturismo.

Antes de abordarmos especificamente as possibilidades de divulgação pelo Geoturismo, é necessário identificar os motivos que tornam essa divulgação uma tarefa um pouco mais difícil nas Geociências. Alguns autores (UCEDA,1996; NEWSOME; DOWNLING, 2006; MANSUR, 2009; PEREIRA, 2010; PONCIANO, 2015) apontam que as dificuldades de divulgação nas Geociências são potencializadas por um baixo interesse do público leigo pelos conhecimentos geológicos, e seguem ressaltando que os principais motivos para isso são: (1) a menor atratividade que a geodiversidade exibe, frente aos elementos bióticos da Natureza, uma vez que estes últimos possuem maior variedade de cores, sons e interações; (2) o maior foco dos geólogos em atividades relacionadas com a exploração econômica de recursos minerais e energéticos; (3) a inacessibilidade da linguagem geológica para a maior parte da população; (4) a abordagem dos conteúdos geocientíficos, predominantemente restrita às escolas e universidades, onde o ensino de tais temas é muitas vezes ignorado devido à falta de formação dos professores e à grande resistência dos estudantes frente aos termos técnicos e pouco usuais; e (5) no caso específico do Brasil, contribuem também para a baixa divulgação, a ausência de catástrofes de cunho estritamente geológico, o que reduz o interesse pelo conhecimento mais profundo das Geociências.

Para superar tais problemas e diminuir o distanciamento entre as Geociências e a população, Mansur (2009) defende uma abordagem holística, onde os sistemas bióticos e abióticos estão interligados e devem ser tratados de maneira integrada. Outra contribuição nesse sentido é a de Ponciano $(2015,2018)$, onde a autora propõe a utilização da Geomitologia e da Geopoética como formas de divulgação do 
conhecimento geocientífico. A utilização dessas duas abordagens na divulgação das Geociências é uma forma eficiente de recuperar a conexão natural entre as pessoas e os lugares, contribuindo de maneira significativa com as práticas de Geoconservação, tais como o Geoturismo.

Quais seriam então as possibilidades de utilizar essas abordagens em atividades e roteiros geoturísticos? De acordo com Ponciano $(2015,2018)$ a Geomitologia pode ser utilizada como forma de integrar o conhecimento científico com os aspectos culturais e sociais de um local. O termo Geomitologia foi inicialmente proposto pela geóloga Dorothy Vitaliano em 1968, enfocando os mitos que explicam a ocorrência de eventos geológicos. Posteriormente, a abrangência desses mitos foi ampliada para abarcar a origem dos fósseis e de outros elementos da geodiversidade (minerais, rochas, solos e diversos depósitos que são o suporte da vida na Terra), mas apesar de não ser uma área recente, a Geomitologia ainda é pouco estudada e utilizada no Brasil. Relacionar os mitos com a formação geológica dos locais é uma excelente alternativa para a divulgação e popularização das Geociências, uma vez que utiliza as representações culturais das comunidades do local para promover a reconstrução do elo entre o homem e o ambiente.

Enquanto a Geomitologia se baseia nos mitos de um local para a reconstrução da Topofilia, a Geopoética utiliza as Artes para resgatar esse afeto. Em sua vertente mais abrangente, a Geopoética está de acordo com a linha de pensamento desenvolvida por Kenneth White, que em 1979 associou este termo com as diversas formas de relação dos seres humanos com o planeta Terra (PONCIANO, 2018). Para Kozel (2012), há na Geopoética uma convergência e reciprocidade entre a poesia, o pensamento e a ciência. Essa convergência ajuda a romper as fragilidades inerentes à fragmentação e dualidade do conhecimento, que muitas vezes é visto como algo afastado da vida e da cultura de um local. Segundo o mesmo autor, por meio da integração das Artes com a ciência, é possível vislumbrar a inteireza do ser humano no mundo e refletir sobre a vida na Terra e o papel da nossa sociedade nesse contexto. Essa reflexão do mundo pela Geopoética propõe o resgate da sua inteireza por meio de linguagens diferenciadas e sensíveis, como as Artes visuais, a música, os odores, a expressão oral e escrita, em combinação e sintonia.

A integração dessas diferentes formas de expressão das Geociências aos roteiros Geoturísticos amplia as possibilidades de divulgação geocientífica e contribui diretamente para a Geoconservação. Visando contribuir com a divulgação da Geologia e da Paleontologia, foi criado em 2015, na Universidade Federal do Estado do Rio de Janeiro (UNIRIO), o grupo de performances artísticas "GeoTales" e o grupo de pesquisa "Geomitologia, Geopoética e Paleontologia Cultural: interfaces entre as Geociências e as Artes", ambos com o objetivo de promover a conservação do Patrimônio Natural e Cultural brasileiro por meio da ampliação da divulgação das Geociências, do empoderamento feminino e da valorização das culturas indígena e afro-brasileira (SANTOS et al., 2017; PONCIANO, 2018). Em 2017, o GeoTales passou a participar também dos projetos associados ao Programa de PósGraduação em Ecoturismo e Conservação (PPGEC - Mestrado profissional) da UNIRIO. A integração do GeoTales com as pesquisas realizadas no PPGEC gerou, dentre outros produtos, o roteiro geoturístico aqui apresentado. Atualmente, no período de 2018 a 2020, o GeoTales desenvolve três projetos de extensão da UNIRIO ("Geomitologia da América do Sul: as rochas contam a nossa história"; "GeoTales: conservação do Patrimônio Natural por meio dos repentes da Terra" e 
"Geopoética do Orun ao Ayiê: a Terra que atravessa o tempo"). As histórias em prosa e verso utilizadas como base para a criação das performances são unidas numa coletânea denominada repertório geopoético, criado a partir de um levantamento de mitos de diversas origens (especialmente indígenas e afrobrasileiros) e poemas na língua portuguesa (de autores brasileiros, africanos e portugueses) e inglesa, que apresentam diversas possibilidades de correlação dos seus temas com conceitos associados com as Geociências. Destaca-se que as histórias e os poemas são parcialmente modificados para o uso nas performances geopoéticas, usualmente pela inclusão de mais conteúdo científico e diminuição do seu tamanho original, a fim de destacar as partes que podem ser mais diretamente correlacionadas com as Geociências (PONCIANO, 2018). Parte do material produzido pelo GeoTales, além de artigos e livros digitais, é disponibilizado por meio do Instagram (@geotales, @projetomulheresdaterra, @geo_orunaoaiye, @luasdeashanti), site (http://geotalesunirio.wixsite.com/geotales), página do Facebook (GeoTales UNIRIO) e canal do Youtube (GeoTales UNIRIO), a fim de ampliar o acesso aos materiais produzidos pelo grupo.

Como as atividades do GeoTales possuem temáticas variadas, destacamos aqui as que se relacionam com os mitos do Rio de Janeiro, associadas ao projeto Geomitologia da América do Sul, que tem como objetivo coletar e recriar histórias em prosa e verso que estejam relacionadas com as montanhas, rochas e paisagens mais excepcionais do Rio de Janeiro, devido aos seus valores científico, didático, estético, cultural, turístico e histórico. O primeiro local analisado pelo GeoTales foi a Pedra da Onça ou Pedra Maracajá, localizada na llha do Governador. Nas pesquisas do GeoTales foram encontradas diversas variantes da história sobre a Pedra da Onça, que possuíam em comum a parte em que uma índia mergulha nas águas da Baía de Guanabara e deixa seu gato maracajá na pedra, onde ele acabou morrendo na longa espera por seu retorno. Em algumas histórias o maracajá acabou petrificado no topo da pedra. A partir dessas variantes o GeoTales desenvolveu novas narrativas, onde foram incluídos os conceitos de fossilização e a formação geológica da Baía de Guanabara e da Ilha do Governador (ARAUJO et al., 2017).

A segunda história analisada pelo GeoTales foi justamente a do gigante adormecido ou gigante de pedra, sendo aqui o momento em que os projetos se encontraram (ARAUJO; PONCIANO, 2018). Essa história é uma das mais conhecidas pela população do Rio de Janeiro, e se baseia na disposição das formas de relevo que compõem a paisagem carioca, envolvendo diretamente a área de estudo do nosso roteiro. Ao serem observadas da entrada da Baía de Guanabara e de outros pontos do Rio de Janeiro e de Niterói, as rochas que formam o relevo litorâneo carioca aparentam ter o formato de um gigante deitado sobre o continente. Em alguns pontos de observação do relevo, sobretudo naqueles localizados na entrada da Baía de Guanabara, a configuração das rochas passa a impressão de que a Pedra da Gávea é a cabeça do Gigante e seus pés estão na Urca, no morro do Pão de Açúcar (Figura 1a). Destacamos que outras conformações do gigante também são propostas para outras partes de morros na cidade do Rio de Janeiro (Figura 1b), tendo em comum que em todas as opções uma combinação dos morros localizados no litoral da cidade dá origem à silhueta de um gigante deitado. Esta visualização de um gigante adormecido nos morros ocorre também em outros locais, como em Ontário, no Canadá, onde a história envolve a cobiça dos homens brancos por uma mina de prata que era explorada pelos povos indígenas (PIPER, 1924). 


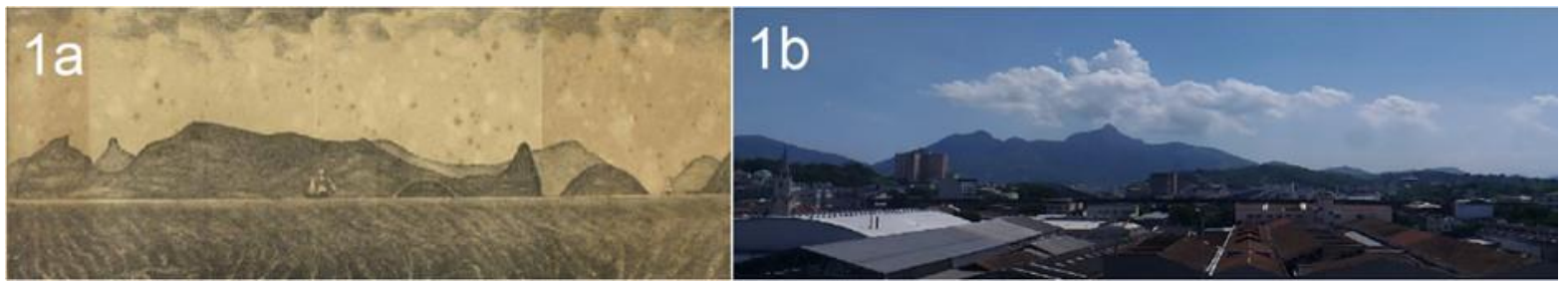

Figura 1: (a) Morros cariocas em uma das representações do gigante adormecido, visualizado a partir da entrada da Baía de Guanabara. Fonte: Souza (1882). (b) Outra representação do gigante adormecido, capturada a partir de um edifício na Zona Portuária do Rio de Janeiro. Notar como a urbanização está encobrindo a visualização do gigante Fonte: Foto de Luiza Ponciano (2019).

Figure 1: (a) Rio de Janeiro hills in one of the representations of the sleeping giant, pictured from the entrance of the Guanabara Bay. Source: Souza (1882). (b) Another representation of the sleeping giant, captured from a building in the Portuary zone of Rio de Janeiro. It is possible to observe the urbanization covering the view of the giant. Source: photo by Luiza Ponciano, (2019).

A história do gigante adormecido foi retratada em diversos momentos da história recente do Rio de Janeiro e do Brasil, destacando-se na atual década: a campanha publicitária da marca de uísque escocês Johnnie Walker, em parceria com as agências Neogama/bbh e The Mill, de 2011; o enredo "Um Rio de Mar a Mar: do Valongo a Glória de São Sebastião" da escola de Samba Portela, em 2014, onde o último carro alegórico foi chamado de "o gigante adormecido que acordou"; e no livro "Eram os deuses cariocas?" de Leonardo Leite, escrito em 2016 e em Melo (2013). Além dos exemplos acima, a história do Gigante adormecido possui variantes mais antigas, tais como Lira (1951), Souza (1882) e Dias (1851). Este último é o poema "Gigante de Pedra" (de Gonçalves Dias), do qual foi extraído um trecho, que foi parcialmente modificado para ser apresentado pelo grupo GeoTales na primeira parada do roteiro geoturístico na Urca: "Gigante orgulhoso, de feroz semblante / Num leito de pedra lá estás a dormir! / Em duro granito repousa o gigante / Que os raios somente puderam fundir. [...] / Com os braços no peito, cruzados, dengosos / Mais alto que as nuvens, os céus a encarar / Seu corpo se estende por montes rugosos / Seus pés faceiros se elevam do mar! [...] / E lá na montanha, deitado dormindo / Alteia o gigante - nem pode acordar! / Cruzados os braços de ferro fundido / A cabeça nas nuvens, os pés sobre o mar?'.

Tendo como inspiração as narrativas citadas acima e as experiências vivenciadas nas apresentações do GeoTales, foi produzida de forma autoral a história "Andinus - o gigante do Sul" (ARAUJO; PONCIANO, 2018), que também fez parte da performance geopoética realizada na primeira parada do roteiro geoturístico na Urca:

"Era uma vez... uma história do passado da Terra, quando ela era habitada por gigantes, há milhões de anos... Muitos desses gigantes são restos ou vestígios de animais enormes que realmente existiram e que encontramos hoje em dia como fósseis! Vocês já devem ter visto nos filmes as preguiças gigantes, os mastodontes, os tatus e até os tigres dente-de-sabre! Mas antigamente algumas pessoas também enxergavam outros tipos de gigantes que não tem a ver com os fósseis, na silhueta das rochas aqui do Rio de Janeiro... essa é a história do gigante adormecido, que nós ainda podemos ver aqui nas nossas montanhas! Conta a história que aqui no Rio de Janeiro existia um gigante feito de rochas... no início, quando ele nasceu, o seu corpo era todo de magma, que foi resfriando e se transformou em uma rocha que chamamos de granito, ainda lá embaixo, nas 
profundezas da crosta... ele continuou se desenvolvendo, e um tempo depois, por causa da movimentação das placas tectônicas que formaram o supercontinente Gondwana, há uns 600 milhões de anos, o aumento da temperatura e da pressão relacionado com esta colisão levou ao metamorfismo de algumas rochas, que foram transformadas em gnaisse! A gente chama elas de gnaisse facoidal, por causa dos "olhinhos" que parecem ter, que são os minerais achatados! Tem uns que até lembram os olhos puxados dos povos indígenas... Depois disso teve a separação dos continentes e os processos de soerguimento destas rochas até aqui a superfície, onde os desgastes causados pelos ventos, chuvas, e outros fatores permitiram que as rochas mais resistentes dessem origem ao Pão de Açúcar, Morro da Urca, Corcovado, Pedra da Gávea e outros lugares maravilhosos do Rio de Janeiro. Segundo a história dos Tamoios essas paisagens mais famosas são justamente o gigante deitado! Eles dizem que quando o gigante finalmente chegou aqui na superfície, depois de milhões de anos embaixo da terra, ele estava tão cansado que deitou para tirar uma soneca e acabou ficando por aqui, adormecido! A Pedra da Gávea é a sua cabeça, o Corcovado é a sua cintura e o Pão de Açúcar nada mais é do que as suas pernas e pés dobrados! Dessa forma podemos ver o gigante até hoje, na Geodiversidade que serve de suporte para diversas plantas, como 0 pau-brasil, e moradia para animais, como os tatus (agora de menor tamanho), até a hora que ele resolver acordar e sair caminhando por aí!..."

\section{A evolução da paisagem carioca e a formação geológica do gigante adormecido}

Para compreendermos a formação geológica do gigante adormecido é necessário entender os eventos e processos que marcaram a evolução da paisagem carioca. Esses eventos produziram no Rio de Janeiro um relevo marcado pela irregularidade e pelo contraste entre maciços costeiros, planícies fluviais e/ou marinhas e pela presença da Baía de Guanabara. De acordo Valeriano et al. (2012) a Geologia e as paisagens cariocas e fluminenses são o resultado de uma sucessão de eventos, sendo o primeiro deles a colisão entre blocos continentais que deu origem ao Paleocontinente Gondwana (Figura 2a e 2b) entre cerca de 630 - 540 milhões de anos antes do presente. Esse evento foi marcado por intensos processos de deformação e metamorfismo que deram origem a boa parte das rochas cariocas. 


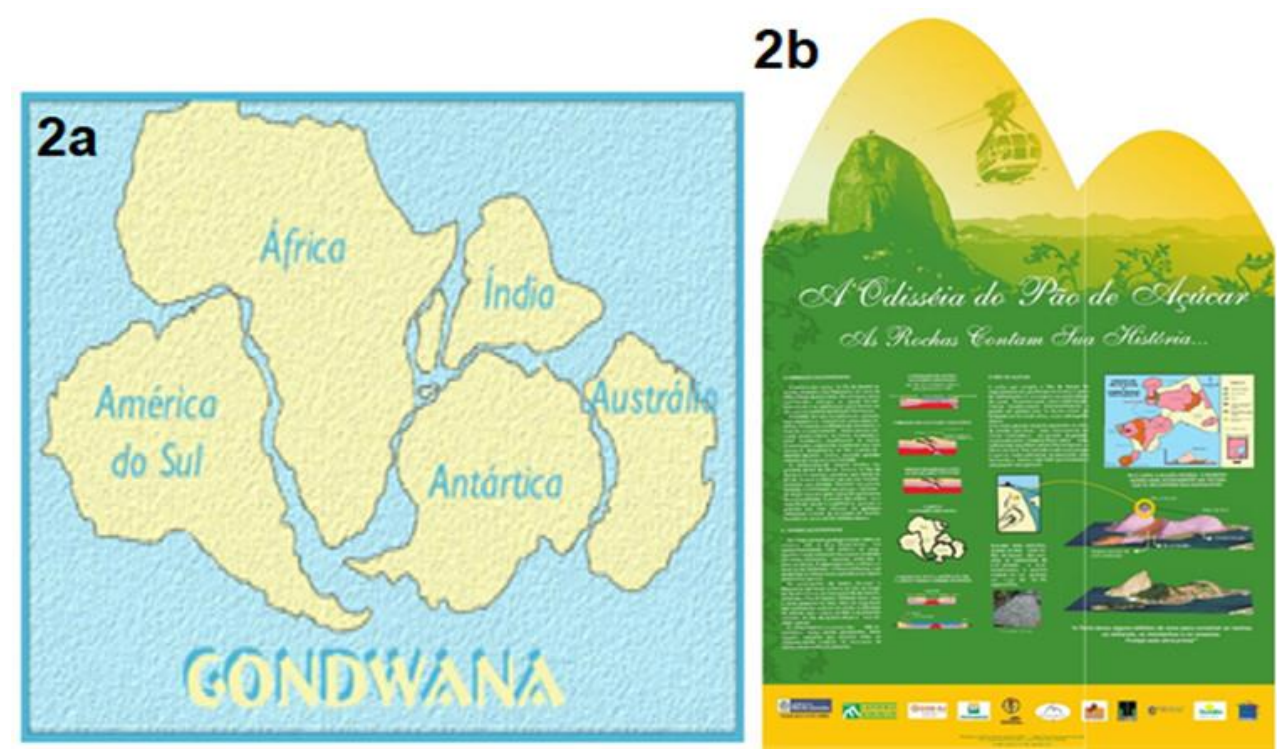

Figura 2: (a) Mapa esquemático do Paleocontinente Gondwana. (b) Placa do Projeto Caminhos Geológicos, do Departamento de Recursos Minerais do Estado do Rio de Janeiro (DRM-RJ).

Fonte: (a) http://www.fgel.ueri.br/dgrg/webdgrg/Timescale/Tectonica global.html. (b) Valeriano (2006).

Figure 2: (a) Schematic map of the Paleocontinent Gondwana; b) Panel of the Projeto Caminhos Geológicos, Department of Mineral Resources of the State of Rio de Janeiro (DRM-RJ).

Source: (a) http://www.fgel.uerj.br/dgrg/webdgrg/Timescale/Tectonica global.html. (b) Valeriano (2006).

O evento colisional foi seguido de um período de relativa estabilidade, que teve seu fim entre 150 - 130 milhões de anos, com a fragmentação do Gondwana e a abertura do Oceano Atlântico. Estes processos de colisão e separação do Paleocontinente são extremamente importantes para compreender os tipos e as formas das rochas cariocas. Apesar da sua importância, estes não foram os únicos eventos responsáveis pela formação das atuais paisagens cariocas. Somam-se a tectônica e ao vulcanismo, um intenso processo de soerguimento, além do intemperismo e da erosão de extensas camadas de rochas e sedimentos. Esses processos são fundamentais para compreender como os gnaisses e granitos, até então soterrados há cerca de $20 \mathrm{~km}$ de profundidade, chegaram à superfície (MANSUR et al., 2008a,b; Valeriano et al. 2012).

Sendo assim, a análise da sucessão de eventos que levou a constituição da Geologia e da Geomorfologia do Rio de Janeiro nos mostra que os processos de desgaste de rochas e minerais são essenciais para a compreensão dessa evolução geológica da cidade. Os processos de intemperismo e erosão permitiram que as rochas mais resistentes estivessem hoje visíveis e dessem origem a famosos pontos turísticos da cidade, tais como: os maciços do Pão de Açúcar e Morro da Urca, do Corcovado e o Arpoador. As evidências do processo erosivo podem ser vistas, por exemplo, nas fraturas por alívio de pressão presentes no morro do Pão de Açúcar.

Sobre a fisiografia da Baía de Guanabara, Valeriano et al. (2012) afirmam que ela abrange três grandes compartimentos geomorfológicos relacionados a um rifte que pertence ao Sistema de Riftes do Sudeste Brasileiro. Os compartimentos estão distribuídos de norte a sul: (1) a borda norte é representada pela Serra do Mar; (2) o interior do rifte pelo Graben da Guanabara; e (3) a borda sul pelos Maciços costeiros, com destaque para a Serra da Carioca, onde se encontram os morros do Pão de Açúcar e do Corcovado. A formação desse rifte no Paleógeno (entre 66 - 23 $\mathrm{Ma})$ foi condicionada pela fragmentação do Gondwana e consequente abertura do 
Oceano Atlântico (VALERIANO et al., 2012) e suas marcas podem ser vistas nos falhamentos e fraturamentos presentes na região da Baía de Guanabara.

É importante destacar também que a formação do Graben da Guanabara foi seguida por processos de sedimentação influenciados pelo intemperismo e erosão de sedimentos associados ao clima tropical litorâneo característico da região. A deposição de sedimentos preencheu o graben durante Paleógeno e o Neógeno (entre 23 - 2,5 Ma). Durante o Quaternário (2,5 Ma - atualidade) as oscilações do nível do mar associadas ao fim das glaciações ocorridas no Pleistoceno (entre 2,5 0,0117 Ma) foram responsáveis pela formação das planícies costeiras e pela formação da Baía de Guanabara, de idades Pleisto-Holocênicas.

Já os últimos 2.500 anos, sobretudo os três séculos mais recentes, são marcados pela intensa atuação humana. O conjunto de ações antrópicas é responsável por diversos processos que transformaram a antiga paisagem natural em uma paisagem cultural, que expressa não só as belezas, mas também as contradições da sociedade carioca. Essas contradições, exemplificadas principalmente pelos nítidos contrastes socioespaciais, não impediram, contudo, que a Organização das Nações Unidas para a Educação, a Ciência e a Cultura (UNESCO) concedessem à cidade o título de Patrimônio Cultural da Humanidade, na categoria de Paisagem Cultural (UNESCO, 2016).

Depois de analisarmos como se deu a evolução da paisagem carioca, podemos agora focar na história evolutiva de um dos pontos mais famosos que compõem o contorno do gigante adormecido: o Pão de Açúcar, um dos pontos turísticos mais conhecidos da cidade do Rio de Janeiro. A formação e a apropriação do morro como Patrimônio pela população carioca estão diretamente relacionadas com os processos evidenciados anteriormente, sendo possível observar em suas estruturas as marcas dos eventos geológicos. As rochas do Pão de Açúcar fazem parte do embasamento cristalino da região, possuem idade Neoproterozoica (560 Ma) e estão classificadas como estruturas colisionais, inseridas na Suíte Rio de Janeiro (SILVA; CUNHA, 2001; VALERIANO et al., 2012) e extensionais, devido a presença de diques de diabásio do Cretáceo (130 Ma).

O Pão de Açúcar é formado pelas seguintes rochas (Figura 3): o gnaisse facoidal (um biotita-microclínio gnaisse) com cerca de 560 milhões de anos; o kinzigito, presente entre os morros do Pão de Açúcar e da Urca; veios graníticos; veios de quartzito, que evidenciam os efeitos do processo de compressão pelo qual a estrutura do morro passou; e os diques de diabásio, instalados posteriormente (Era Mesozoica), associados ao faturamento e separação do Gondwana (VALERIANO; MAGALHÃES, 1984).

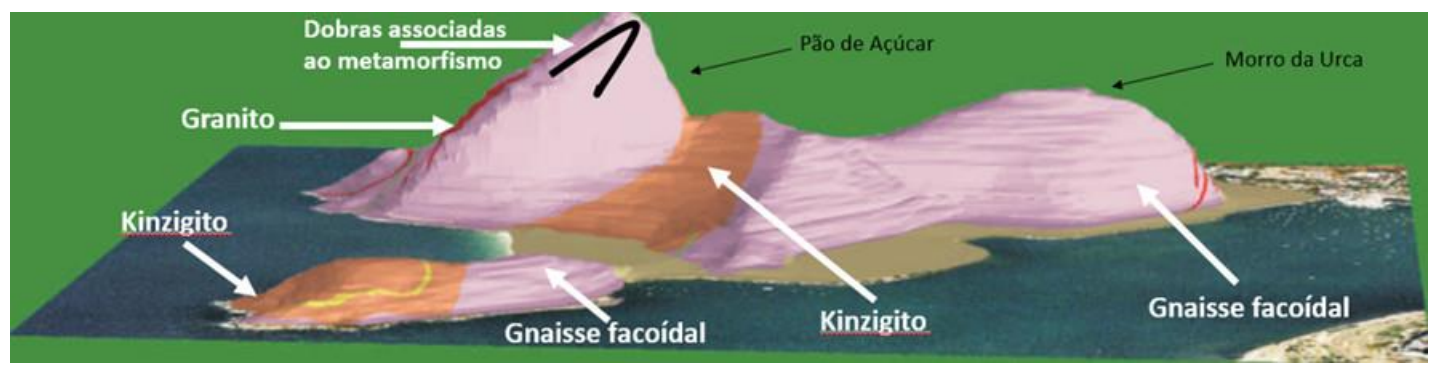

Figura 3: Rochas presentes nas estruturas dos Morros do Pão de Açúcar e da Urca.

Fonte: Adaptado de Valeriano (2006).

Figure 3: Rocks found in the structures of the Sugar Loaf and Urca hills.

Source: Adapted from Valeriano (2006). 
Trataremos com maior destaque o gnaisse facoidal e o kinzigito, por estes representarem as rochas mais predominantes nos morros do Pão de Açúcar e da Urca (Figura 3). O gnaisse facoidal é um tipo de rocha metamórfica com ampla presença nos municípios do Rio de Janeiro e Niterói. Assim como outros gnaisses e granitos, tem sua origem relacionada aos processos de colisão dos blocos continentais que formaram o Paleocontinente Gondwana, processo ocorrido há cerca de 600 milhões de anos (VALERIANO, 2006; VALERIANO, 2007a,b; VALERIANO et al., 2012). O aumento da temperatura e da pressão promovida pela colisão levou à fusão das rochas e posteriormente ao metamorfismo e deformação delas. O gnaisse facoidal é uma rocha metamórfica ortoderivada, produto da colisão que levou à formação do Gondwana (MANSUR et al., 2008a,b).

Já o kinzigito é um granada-biotita gnaisse, ou seja, é uma rocha originada a partir do metamorfismo dos materiais sedimentares que separavam os continentes antes da colisão para a formação do Gondwana (MOTTA, 2017). O choque que levou à formação do Paleocontinente foi responsável pelo aumento de temperatura e pressão que metamorfizou os materiais sedimentares presentes no fundo do antigo oceano. A posterior separação dos continentes, somada ao intemperismo e à erosão provocadas pela exposição das rochas à atmosfera, hidrosfera e biosfera, originou a paisagem do Rio de Janeiro.

\section{O gnaisse facoidal e a história do Rio de Janeiro}

Além da sua relação com a origem das paisagens naturais do Rio de Janeiro, o gnaisse facoidal e os morros do Pão de Açúcar e da Urca também possuem importância histórica e cultural para a cidade. Esta rocha está presente em diversas construções históricas espalhadas pelo Rio de Janeiro, sobretudo, em seu Centro Histórico, sendo classificada por Mansur et al. (2008a) como "A mais carioca das rochas". Já os Morros do Pão de Açúcar e da Urca, juntamente com o morro Cara de Cão, proporcionaram aos portugueses as condições necessárias para a fundação da cidade. Esse tópico destaca a importância dos morros e de sua rocha predominante para a fundação e evolução da cidade e do bairro da Urca.

Antes de se tornar a metrópole socialmente fragmentada e segregada que é hoje em dia, o município do Rio de Janeiro iniciou seu desenvolvimento em uma pequena restinga localizada entre os morros do Pão de Açúcar, Urca e Cara de Cão, tendo assim, como seu local inicial, o atual bairro da Urca. Em 1ํ de março de 1565, o bairro se tornou o primeiro núcleo de ocupação da Cidade do Rio de Janeiro, tendo como marcos de sua fundação, a chegada do Capitão português Estácio de Sá e a realização de uma missa pelo Padre Anchieta. Esses eventos marcam a fundação do Rio de Janeiro como cidade e o início da colonização portuguesa em terras cariocas, que afetou diretamente a vida de milhares de indígenas (MOTTA, 2017). Os povos que já habitavam o local passaram a sofrer com as doenças, as guerras e a organização territorial imposta pelos portugueses.

A fundação da cidade foi motivada pela ocupação francesa em algumas ilhas da Baía de Guanabara, com destaque para a Ilha de Villegaignon, localizada próxima ao aterro do Aeroporto Santos Dumont (PRATES, 2010). Para enfrentar os franceses, os colonizadores portugueses se instalaram na área hoje ocupada pelo bairro da Urca. A escolha desse local para a fundação da cidade foi uma escolha estratégica, segundo o Instituto do Patrimônio Histórico e Artístico Nacional (IPHAN, 1973), uma vez que os morros do bairro protegiam as instalações portuguesas de 
possíveis ataques franceses. O local é ocupado até os dias de hoje por instalações militares herdadas do período em questão, destacando-se aqui a Fortaleza de São João, onde estava o monumento do Marco de Fundação da Cidade de São Sebastião do Rio de Janeiro, tombado pelo IPHAN (Figura 4).

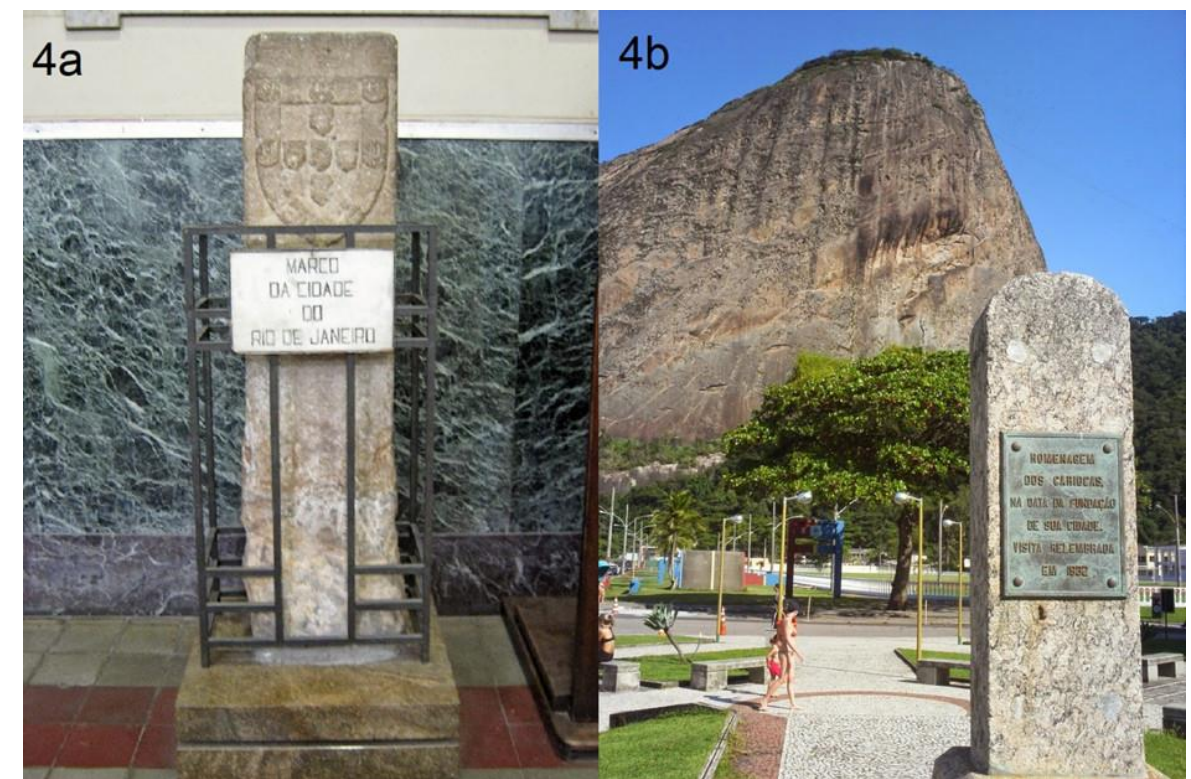

Figura 4: (a) Marco de fundação da Cidade do Rio de Janeiro (b) Monumento em homenagem à Fundação da Cidade do Rio de Janeiro na Praça da Fundação, no interior da Fortaleza de São João - Urca (RJ), com o Morro do Pão de Açúcar ao fundo. Fonte: (a) Halleypo/Wikimedia Commons Sem data. Disponível em: www.multirio.rio.ri.gov.br (b) Korytowski (2009).

Figure 4: (a) Founding Monument of the Rio de Janeiro city; (b) Monument in honor of the Foundation of the city of Rio de Janeiro in the Foundation Square, inside the Fortaleza de São João - Urca (RJ), with the Sugar Loaf hill in the background. Source: (a) Halleypo/Wikimedia Commons - Sem data. Disponível em: www.multirio.rio.ri.gov.br (b) Korytowski (2009).

De acordo com DUARTE (2019), o marco de fundação foi localizado inicialmente no Morro Cara de Cão. O monumento foi talhado em granito, possivelmente no ano de 1565 e é um marco comemorativo do início de posse e fundação da cidade do Rio de Janeiro pelos portugueses. O monumento passou por diversas trocas de local: ainda no século XVI o marco foi trasladado para o Morro do Castelo, primeiro núcleo efetivo de ocupação urbana da cidade; em 1843 passou a se localizar na parte externa da Igreja de São Sebastião, que havia sido reformada pelos Capuchinhos Italianos, responsáveis pela igreja a partir de então; em 1922, após o desmonte do Morro do Castelo, o monumento foi colocado na Praça da Explanada do Castelo; posteriormente, ele foi transferido para a Igreja dos Capuchinhos, na Tijuca; e, por fim, foi instalado na Igreja de São Sebastião, na Rua Haddock Lobo, também no bairro na Tijuca.

A transferência do núcleo urbano da cidade para o Morro do Castelo (1567) fez com que o atual bairro da Urca ficasse conhecido como Cidade Velha, passando a manter apenas funções militares, que caracterizaram o local até a virada do século XIX para o XX, quando a expansão urbana da cidade do Rio de Janeiro atingiu o bairro (MOTTA, 2017). A Urca é habitada por uma população de média e alta renda, integra a Zona Sul da cidade e é considerado um dos bairros mais tranquilos e bucólicos do Rio de Janeiro. Devido às características naturais do local, a fundação e ocupação do bairro exigiram uma série de intervenções urbanísticas, 
principalmente a construção de aterros. Até o século XIX a Urca não existia, as águas da Baía de Guanabara entravam em contato direto com os morros do Pão de Açúcar e da Urca, e suas instalações militares eram acessadas apenas por embarcações. Somente no Século XIX o local começa a receber os primeiros prédios institucionais, como o Hospício D. Pedro II (1852), onde hoje funciona a Universidade Federal do Rio de Janeiro; o Batalhão de Engenheiros (1856); a Escola Militar de Aplicação (1860); e o Imperial Instituto de Meninos Cegos (1872), atual Benjamin Constant. Dentre os prédios construídos no final do século XIX, destaca-se o Palácio dos Estados, da Exposição de 1908, utilizado para a comemoração do Centenário da Abertura dos Portos às Nações Amigas e da chegada da Família Real ao Brasil. Neste prédio estão hoje localizadas a Companhia de Pesquisa de Recursos Minerais (CPRM) e o Museu de Ciências da Terra (MCTer). Embora tenha sido concluído para a exposição, o prédio foi originalmente projetado para Faculdade de Medicina em 1880, mas a falta de recursos paralisou as obras até a Proclamação da República, em 1889 (TOSATTO, 1997). Com a mudança na política do país, as obras foram retomadas para que o prédio recebesse a Escola Superior de Guerra. Em 1892 a falta de recursos paralisou as obras novamente. Entre 1880 e 1907 a construção foi marcada por paralisações e pela morosidade, sendo concluída efetivamente em apenas oito meses, para a Exposição de 1908.

O Palácio dos Estados foi projetado em estilo neoclássico pelo engenheiro Antônio Paula de Freitas. Em sua construção deveriam ser utilizados apenas materiais nacionais, provenientes principalmente das pedreiras de São Diogo, próxima à Zona Portuária, e do bairro de Botafogo. No revestimento e na ornamentação do prédio predomina o gnaisse facoidal, uma das rochas mais abundantes da cidade. Apesar disso, a proposta inicial não foi cumprida. A morosidade e as paralizações das obras fizeram com que o prédio só fosse concluído 26 anos depois de ter sido projetado, quando Antônio Freitas já não as comandava. Na conclusão, para a Exposição de 1908, foram utilizados materiais importados, tais como a cerâmica italiana, no salão principal. A Exposição de 1908 foi a primeira grande exposição do país e exigiu a adaptação e construção de um espaço específico para o evento, o bairro da Urca. A escolha do local foi pelas diversas construções que poderiam ser reaproveitadas ou adaptadas, o que diminuiu o custo do evento. A Exposição foi realizada entre os dias 11/08/1908 e 15/11/1908, e o Palácio dos Estados serviu como base para os materiais expostos por diversos Estados brasileiros, exceto aqueles que tinham seus próprios pavilhões (Distrito Federal, São Paulo, Minas Gerais e Bahia) (TOSATTO, 1997; RIO DE JANEIRO, 2012).

As transformações realizadas na Urca não se limitaram aos preparativos da Exposição de 1908. Posteriormente, entre os anos de 1912 e 1913, durante o mandato de Serzedelo Correia, foram concedidas e iniciadas as construções das infraestruturas que iriam compor o bondinho do Pão de Açúcar. O bondinho foi inicialmente projetado para três ramais: Morro da Urca, Pão de Açúcar e Morro da Babilônia, mas o projeto final contou apenas com os dois primeiros ramais (RIO DE JANEIRO, 2012). As modificações urbanísticas continuaram sendo realizadas até a década de 1970, com alterações nas estruturas e funções do bairro. Entre os anos de 1919 e 1922 uma série de convênios foi assinada, visando o aterramento e a construção efetiva de um bairro residencial. Em 1921 a S.A. Empresa da Urca foi designada para a construção de um cais, ligando a Praia da Saudade à Fortaleza de 
São João. No ano de 1922, o Prefeito Carlos Sampaio tinha como uma das suas principais tarefas, o preparo da cidade do Rio de Janeiro para o evento que marcou o 1ํㅡㄹ Centenário da Independência do Brasil (ABREU, 2013). Dentre as obras previstas para sua gestão estavam um novo aterramento no bairro da Urca; a construção da Avenida Portugal; o aproveitamento do pavilhão de Minas Gerais da Exposição de 1908 para a construção da Escola Minas Gerais; o aterro da antiga Praia da Saudade; e a abertura da Avenida Pasteur (RIO DE JANEIRO, 2012).

No final da mesma década, foi projetada a construção de um bairro universitário na Urca. Esse projeto fazia parte dos objetivos de modelação e embelezamento do Plano Agache, elaborado na segunda metade da década de 1920, mas a construção não foi efetivada. Nas décadas seguintes (1930 e 1940) o bairro ficaria conhecido pela presença do Cassino da Urca. A cultura associada aos jogos atraiu a atenção das classes mais altas do Rio de Janeiro e dos turistas, perfil relativamente mantido pelo bairro até os dias atuais. O cassino foi fechado na década de 1940, após a proibição de jogos de azar em todo o Brasil. O prédio permaneceu desativado até o ano de 1953, quando passou a integrar as estruturas da TV Tupi, extinta em 1981. Desde então uma série de disputas marcaram as definições da posse e do uso do edifício, que foi tombado em 1988 e destombado posteriormente (RIO DE JANEIRO, 2012). Essas disputas se desenrolaram até os anos 2000. De acordo com Niklas (2017), o fim da TV Tupi deu inicio ao abandono do prédio, que foi passado para as mãos da prefeitura até o ano de 2006, quando foi cedido ao Istituto Europeo di Design (IED). O IED foi responsável pela revitalização que transformou a parte do complexo voltada para a praia em salas de aula e que pretende, após a conclusão das obras, transformar o antigo palco do Cassino em auditório. Além dos cursos oferecidos, o instituto também possui atividades culturais, com a realização de eventos e exposições em suas dependências.

\section{O Monumento Natural dos Morros do Pão de Açúcar e da Urca}

Para compreendermos a história desta unidade de conservação, é necessário relembrar que os anos de 1970, 1980 e 1990 foram marcados pela pressão por parte da associação de moradores do bairro para que os morros fossem tombados. De acordo com a página da Unidade de Conservação Monumento Natural dos Morros Pão de Açúcar e da Urca - MoNa Pão de Açúcar - na internet (https://www.monapaodeacucar.com/), essa pressão esbarrou durante muito tempo nas indefinições quanto à posse legal dos morros. Isso se deve às constantes mudanças políticas e administrativas pelas quais o município do Rio de Janeiro passou: de Distrito Federal (1861-1960), passando pela Capital do Estado da Guanabara (1960-1975) até a atual condição de Capital do Estado do Rio de Janeiro (desde 1975).

Somente em $1^{\circ}$ de junho de 2006 foi criado pelo Decreto $n^{\circ} 26578$ o Monumento Natural dos Morros do Pão de Açúcar e Urca, inserido no Sistema Nacional de Unidades de Conservação - SNUC, definido pela Lei № 9.985 de 18 de julho de 2000. Os Monumentos Naturais pertencem ao grupo de Unidades de Proteção Integral, ou seja, aquelas onde é permitido apenas o uso indireto dos seus recursos, tendo como objetivo a preservação de sítios naturais raros, singulares ou de grande beleza cênica (BRASIL, 2011). De acordo com o site do MoNa Pão de Açúcar esta categoria é a mais adequada para a proteção dos morros, uma vez que não exige a titularidade da área ao ente que propõe sua criação. O mapa (Figura 5) 
evidencia que praticamente toda a área dos morros está contida na Unidade de Conservação, incluindo a pista Cláudio Coutinho, utilizada como um dos principais acessos às trilhas que levam ao topo do Morro da Urca. Deve ser ressaltado também que, de acordo com o Plano de Manejo do MoNa Pão de Açúcar, a maior parte do bairro da Urca se insere na Zona de Amortecimento da Unidade (RIO DE JANEIRO, 2011).

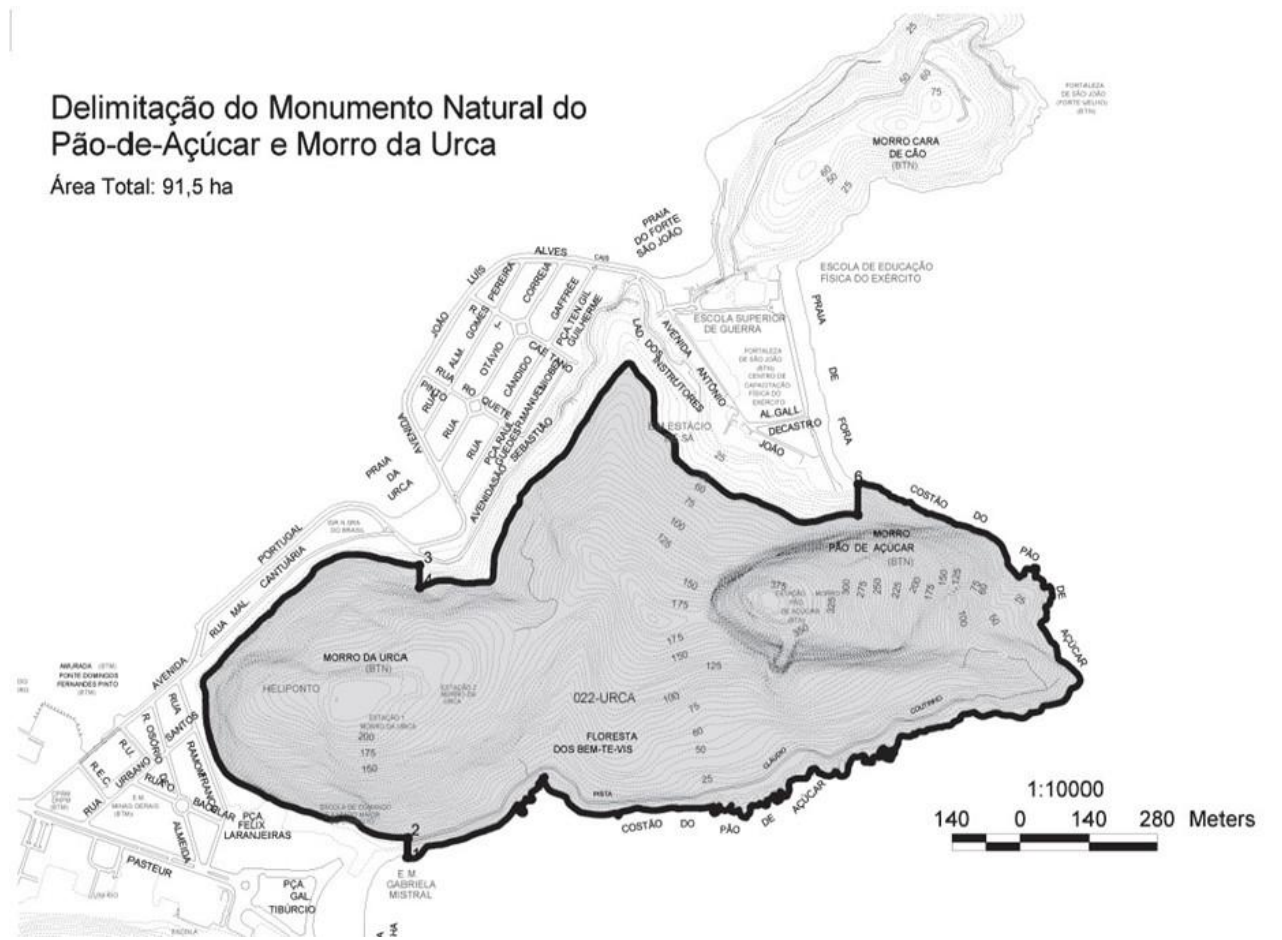

Figura 5: Delimitação da área do MoNa Pão de Açúcar. Fonte: Rio de Janeiro (2011).

Figure 5: Delimitation of the Sugar Loaf Natural Monument. Source: Rio de Janeiro (2011).

Outra questão importante que deve ser ressaltada está relacionada ao tombamento dos morros. Juntamente com o Morro da Babilônia, os morros do Pão de Açúcar, da Urca e Cara de Cão formam o chamado Complexo do Pão de Açúcar. Esse complexo foi tombado pelo IPHAN em 1973, e desde 2012 passou a ser preservado a partir de uma série de ações da Prefeitura do Rio de Janeiro (IPHAN, 2015). Essas ações se dão em consequência do recebimento do título de Patrimônio Mundial na categoria Paisagem Cultural Urbana, concedido pela UNESCO à cidade do Rio de Janeiro e envolvem, além do Complexo do Pão de Açúcar, outras localidades da cidade, tais como o Corcovado, a Floresta da Tijuca, o Aterro do Flamengo, e a Pedra do Arpoador. De acordo com o IPHAN (2015), o conceito de Paisagem Cultural é adotado pela UNESCO desde 1992, sendo incorporado como um novo tipo de reconhecimento de bens culturais, seguindo o previsto na Convenção de 1972, que instituiu a Lista do Patrimônio Mundial. O reconhecimento da paisagem do Rio de Janeiro como Patrimônio da Humanidade representou um marco, pois até então a Lista do Patrimônio Mundial incluía apenas paisagens culturais relacionadas às áreas rurais, sistemas agrícolas tradicionais, jardins históricos e a outros locais de cunho simbólico, religioso e afetivo. 


\section{Roteiro Geoturístico no bairro da Urca / Rio de Janeiro (RJ)}

O Roteiro Geoturístico no bairro da Urca foi elaborado com o objetivo de utilizar as características naturais e urbanísticas do bairro para evidenciar a relação direta entre a evolução da cidade, suas manifestações culturais e suas características geológicas. A cidade do Rio de Janeiro possui diversas possibilidades para a realização de roteiros geoturísticos, pois a maioria dos seus pontos turísticos mais famosos apresenta rochas e formas de relevo de reconhecida beleza cênica.

Para entender a importância da realização dessas atividades em meios urbanos, é necessário compreender que, apesar das transformações impostas pela ação humana, as cidades são, por excelência, o foco do encontro entre o Patrimônio Geológico e a vida cotidiana da população. Nas cidades há uma forte relação entre Patrimônio Geológico, história, cultura, consumo e urbanização, que justifica, portanto, a realização de roteiros geoturísticos nesses locais (LICCARDO et al., 2012). Na Urca, os morros do Pão de Açúcar e da Urca, as praias da Urca e Vermelha e o Museu de Ciências da Terra (MCTer) estão diretamente conectados com a Geologia, Geomorfologia, história e cultura da cidade.

Esses e outros locais da Urca já foram utilizados para a realização de trabalhos de campo (VALERIANO et al., 2000) e de um outro roteiro geoturístico (MANSUR, 2015). Valeriano et al. (2000) propôs cinco paradas, sendo quatro delas (topo do Morro do Pão de Açúcar; topo do Morro da Urca; Pista Cláudio Coutinho; e Morro Cara de Cão) pertencentes ao bairro da Urca. Já Mansur (2015) propôs um roteiro geoturístico inédito, realizado inteiramente na Urca. $O$ trabalho teve como objetivo disponibilizar informações geológicas que permitissem a visita geoturística à Pista Cláudio Coutinho e a outros pontos da área no seu entorno, em um evento voltado para o ensino de Geociências, realizado na UNIRIO.

As informações e pontos sugeridos por estes autores foram consideradas na elaboração do roteiro proposto pelo presente artigo que, assim como nos trabalhos citados, também utilizou as práticas associadas com a Interpretação Ambiental. A interpretação ambiental é apontada por Moreira (2008; 2012; 2014) como um conjunto de práticas inseridas na Educação Ambiental e que tem sua origem vinculada à ideia de como perceber a Natureza. Um dos primeiros autores a trabalhar com o tema (TILDEN, 1977) diz que a Interpretação Ambiental torna o conhecimento e a apreciação da Natureza mais fáceis, por meio da tradução da linguagem científica para o público leigo e para estudantes da educação básica.

Moreira (2014) destaca que a Educação Ambiental deve englobar também a geoeducação, por meio da qual há uma integração entre os estudos da Geografia com a comunicação, o turismo e o ensino escolar. Nesta associação há a incorporação de atividades sócio-pedagógicas internas e externas à educação formal. Para a autora, a geoeducação está apoiada no fato de que o espaço geográfico, em todas as suas perspectivas, é capaz de educar tanto quanto os conhecimentos curriculares específicos. Desta forma, a realização de saídas de campo baseadas nos roteiros se torna uma importante ferramenta para o processo de ensino-aprendizagem. Ressalta-se aqui, que tais atividades representam grandes possibilidades de aprendizado, não só na Geografia, mas em todas as ciências, permitindo abordagens de caráter interdisciplinar. Desta forma, foram selecionados conteúdos das Geociências que também estivessem alinhados com as premissas da Interpretação Ambiental e da geoeducação, sendo integrados às histórias, poemas e performances artísticas realizadas pelo grupo GeoTales. O roteiro inteiro foi 
realizado a pé em cerca de 3 horas, e possui grau de dificuldade baixo, uma vez que não há subidas acentuadas e todo o percurso é realizado em vias asfaltadas e majoritariamente arborizadas.

Foram propostas as seguintes paradas - 1ㅁaa parada - Praia Vermelha: Este ponto teve como objetivo realizar uma apresentação panorâmica dos temas abordados ao longo do roteiro e destacados na introdução do artigo. Foram apresentadas instruções gerais aos participantes quanto a um comportamento adequado ao longo da atividade, tendo em vista sua realização em áreas pertencentes a uma Unidade de Conservação e sua Zona de Amortecimento. Após essas informações iniciais, o roteiro foi iniciado com as performances geopoéticas do trecho do poema "Gigante de Pedra" de Gonçalves Dias (1851), realizada por todas as integrantes do GeoTales em conjunto, e a história "Andinus - o gigante do Sul" (ARAUJO; PONCIANO, 2018), apresentada por Júlia Mayer. Essas performances foram destacadas acima e possuem grande importância nessa etapa inicial do roteiro. A partir delas foram apresentadas de maneira integrada com a Geomitologia e a Geopoética as informações acerca da formação dos morros do Pão de Açúcar e da Urca.

A atividade seguiu ainda na Praia Vermelha (Figura 6) onde foi ressaltado o revestimento do piso, realizado em gnaisse kinzigítico, rico em biotita (placas finas e pretas) e granada (mineral arredondado, vítreo e rosado-avermelhado). O kinzigito observado no piso da Praia Vermelha representa a mesma rocha encontrada na área entre os morros do Pão de Açúcar e da Urca. O desgaste dessa rocha (pelo intemperismo e erosão), realizado pela ação marinha, é responsável pela concentração de granada que era comum na Praia Vermelha e que foi a responsável por seu nome. Nas laterais da praia também podem ser observados outros conceitos, como o intemperismo físico realizado pela raiz das árvores em alguns muros construídos em gnaisse kinzigítico; e o intemperismo químico em estátuas de mármore branco que se encontram no jardim em frente à praia. Os efeitos da poluição urbana sobre esta rocha metamórfica foram vistos principalmente nos dedos dos pés, das mãos e no nariz das estátuas, que apresentam dissolução do carbonato, principal constituinte desse tipo de rocha (MANSUR, 2015).

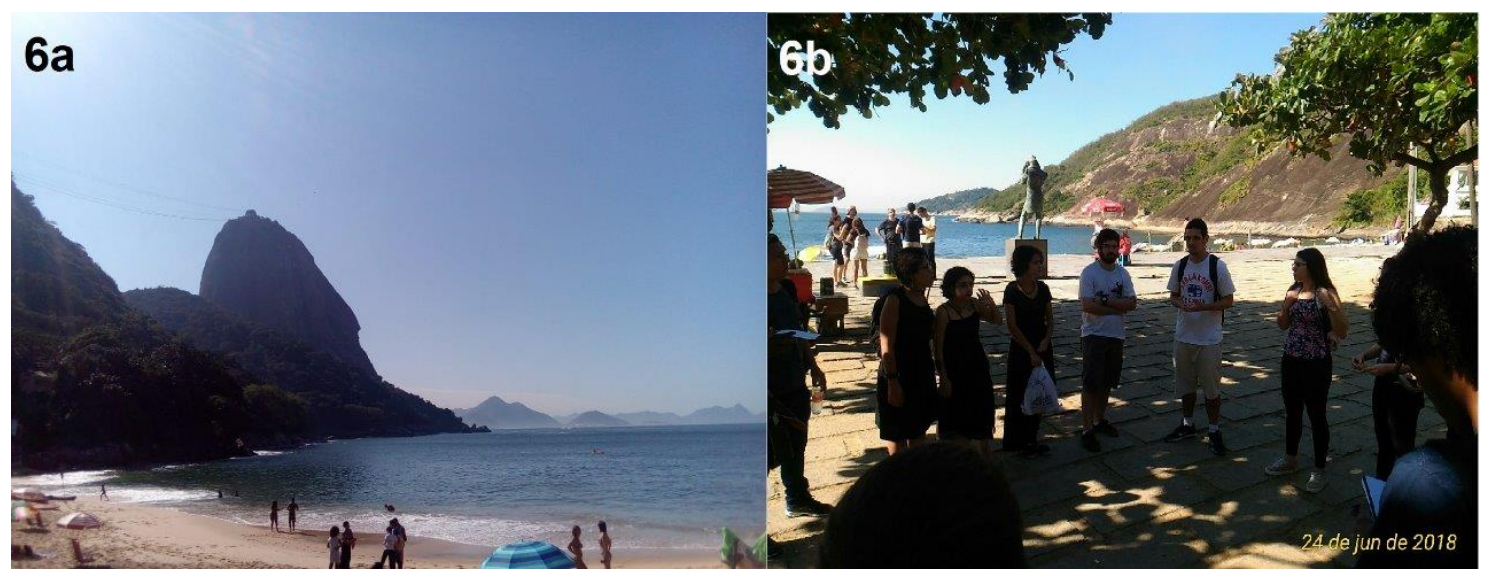

Figura 6: (a) Praia Vermelha, Urca - RJ; (b): Apresentação das informações do roteiro na primeira parada, na Praia Vermelha. Fonte: fotos de Luiza Ponciano (2018).

Figure 6: (a) Praia Vermelha, Urca - RJ; (b): Presentation of the instructions about the geotouristic tour at the first stop, on the Praia Vermelha; Source: photos Luiza Ponciano (2018). 
2 a parada - Pista Cláudio Coutinho: foi iniciada com a performance do poema "Metamorfose", realizada pela autora e integrante do GeoTales, Mallu Oliveira: "Novos ciclos / Um recomeço / Um vai e volta desconcertante / E lá fomos nós / Sozinhas no espaço / Caminhando lentamente na escuridão / Pelos caminhos incertos da vida / Na madrugada fria / Sobe / Desce / Tropeça / Levanta / Tão perto / Mas ao mesmo tempo / Tão longe / E mal sabíamos nós / Que somos / Fortes como uma rocha / Leves como o vento / E livres como as aves". A performance do poema teve como objetivo introduzir o tema metamorfismo, diretamente relacionado com as rochas dos morros do Pão de Açúcar e da Urca.

A parada foi realizada na Pista Cláudio Coutinho, que margeia os morros e foi sugerida por Valeriano et al. (2000) como um dos pontos ideais para um trabalho de campo no local. A partir da pista podem ser observadas as características texturais do gnaisse facoidal, derivadas do metamorfismo e deformação do granito original. Estes processos são concomitantes à orogenia brasileira, que levou à formação da Faixa Ribeira, da qual os morros fazem parte. Essa etapa (Figura 7) utilizou como ponto de apoio a placa do Projeto Caminhos Geológicos, do Departamento de Recursos Minerais do Rio de Janeiro (DRM-RJ). Este projeto tem como objetivo promover a difusão do conhecimento geológico do Estado do Rio de Janeiro, valorizando o Patrimônio Natural e Geológico.

Foram observadas também rochas metassedimentares $e$ as lascas provenientes das quedas de rochas, geradas a partir das fraturas de alívio. $O$ desplacamento destas lascas de rochas é um processo característico da estrutura do Pão de Açúcar, diretamente associada ao alívio de tensão produzido pelo afloramento de rochas que antes se encontravam soterradas por quilômetros de sedimentos e outros materiais rochosos. Essas rochas foram trazidas à superfície pelos movimentos de soerguimento e pela lenta erosão que marcaram a Plataforma Continental Brasileira a partir da fragmentação do Gondwana.

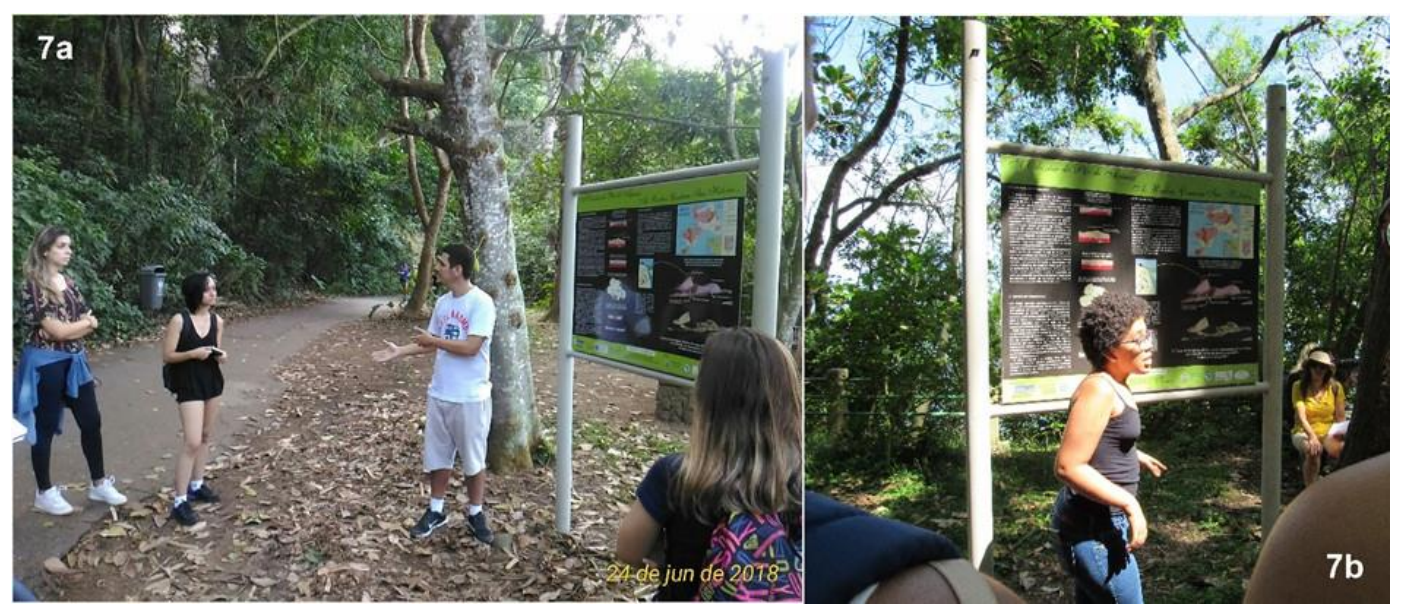

Figura 7: (a) Segunda parada do roteiro, na frente da Placa do Projeto Caminhos Geológicos - DRM-

RJ; (b) Performance do poema "Metamorfose", por Mallu Oliveira.

Fonte: (a) foto de Luiza Ponciano (2018); (b) foto de Julia Mayer (2018).

Figure 7: (a) Second stop of the tour, in the front of the panel of the Projeto Caminhos Geológicos DRM-RJ; (b) Performance of the poem "Metamorfose", by Mallu Oliveira.

Source: (a) photo by Luiza Ponciano; (b) photo by Julia Mayer (2018). 
3 ${ }^{\text {a }}$ parada - Pista Cláudio Coutinho / entrada da Trilha do Morro da Urca: nesta etapa foram apresentadas algumas das práticas que caracterizam as atividades de proteção ambiental realizadas no Monumento Natural dos Morros do Pão de Açúcar e da Urca. Além disso, foram destacadas também algumas características do Sistema Nacional de Unidades de Conservação, trabalhando as diferenças entre conservação e preservação, que caracterizam os dois grupos de categorias de unidades do sistema. Foram ressaltadas algumas ações de manejo realizadas pelo órgão gestor do MoNa Pão de Açúcar, além de aspectos da fauna e da flora (como espécies invasoras, endêmicas, e as ameaçadas de extinção) características da Mata Atlântica importante bioma presente no litoral brasileiro, que hoje se encontra em estágio avançado de degradação.

4a parada - Mureta da Urca: Após leve caminhada pela Rua Ramon Franco, chegamos à Mureta da Urca (Figura 8), que oferece uma visão panorâmica da Baía de Guanabara, permitindo a apresentação dos conteúdos relacionados com a fragmentação do Gondwana e com o rifteamento que originou a configuração atual da baía. Como abertura do tema, foi realizada a performance do poema "Ilha" de Fernando Paixão: "Na orla das curvas ásperas / a água bate / Rebate marolas cansadas / deixa o limo. / A pedra recebe o visgo / em visita / remoendo a forma. / Depois da pele em musgos / vem a carne / contemplar-lhe os ossos. / E a pedra se faz animal.", realizada na atividade do dia 24 de junho de 2018 por Thalyta Angelici e no dia 29 de novembro de 2018 por Luana Santos, ambas integrantes do GeoTales. Nesse ponto foram apresentados o processo e as consequências da fragmentação do Paleocontinente. A vista privilegiada e panorâmica da Baía de Guanabara foi utilizada para evidenciar os processos distensivos e a formação do Rifte da Serra do Mar, do qual fazem parte o Graben da Guanabara e os Maciços Litorâneos. Por fim, fazendo referência ao poema selecionado, foram trabalhados também conceitos e processos referentes à ação marinha sobre a orla do Rio de Janeiro.

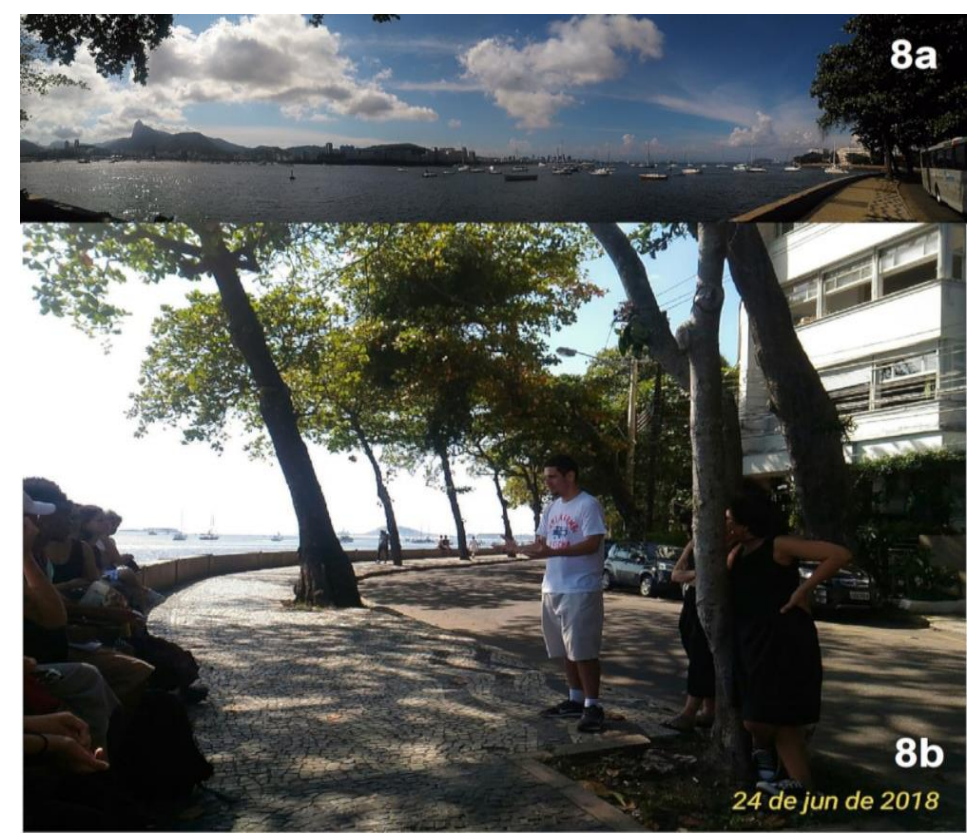

Figura 8: (a) Vista panorâmica da Baía de Guanabara a partir da Mureta da Urca; (b) apresentação dos conteúdos de Geociências na 4⿳亠丷a parada do roteiro.

Fonte: (a) foto de Bernardo Perrota (2019); (b) foto de Luiza Ponciano (2018).

Figure 8: (a) Panoramic view of the Guanabara Bay from the Urca Wall;

(b) presentation of the Geosciences topics in the 4th stop of the geotouristic tour. Source:

Source: (a) photo by Bernardo Perrota (2019); (b) photo by Luiza Ponciano (2018). 
5 a parada - Morro Cara de Cão: localizado em uma área de acesso restrito, protegida pelo Exército Brasileiro, no interior da Fortaleza de São João, o acesso ao morro exige agendamento prévio e foi realizado pelas avenidas Portugal e João Luiz Alves, passando pelo antigo Cassino da Urca e pela praia de mesmo nome. No Morro Cara de Cão pode ser observado o contato litológico entre o gnaisse facoidal e o gnaisse metassedimentar, além de zonas de cisalhamento preenchidas por diques de pegmatito (VALERIANO et al., 2000). Essa parada representa também o início da observação dos aspectos urbanísticos e históricos do bairro. No interior do Forte se encontra a Praça da Fundação e a Praia de Fora, local onde Estácio de Sá desembarcou para fundar a cidade do Rio de Janeiro, marcando assim o início da ocupação portuguesa na cidade.

6ª parada - Quadrado da Urca: acessada pela Avenida Portugal, teve como objetivo evidenciar algumas intervenções urbanísticas que possuem relação com as características geológicas do bairro. A avenida, que não existia até 1922, teve sua construção realizada a partir do aterro da área que ficava entre o Cais da Praia da Saudade e o Morro da Urca (Figura 9a). A construção do cais foi realizada durante os preparativos para a Exposição Nacional de 1908 e tinha como objetivo permitir o acesso ao bairro pelo mar (TOSATTO, 1997). O quadrado da Urca (Figura 9b) funciona hoje como local de atracação de pequenas embarcações e representa o que restou, após os sucessivos aterros, da antiga área marinha isolada da Baía de Guanabara pelo Cais da Praia da Saudade. Do local podemos observar ainda o late Clube do Rio de Janeiro, construído sobre parte da antiga praia da Saudade.

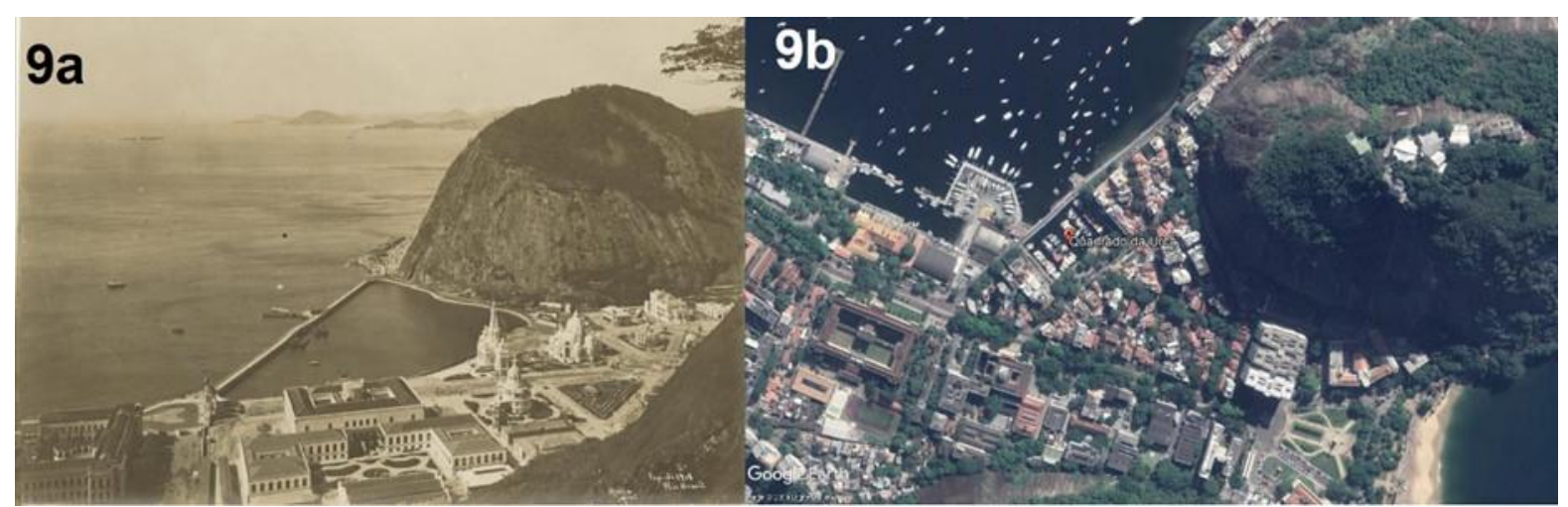

Figura 9: (a) Cais da Praia da Saudade, em 1908; (b) Quadrado da Urca, 2019.

Fonte: (a) Malta. Disponível em: http://brasilianafotografica.bn.br/brasiliana/handle/20.500.12156.1/ 5459; (b) Google Earth (2019).

Figure 9: (a) Praia da Saudade wharf, in 1908; (b) Quadrado da Urca, 2019;

Source: (a) Malta, 1908. Available at: http://brasilianafotografica.bn.br/brasiliana/handle/20.500. 12156.1/5459; (b) Google Earth (2019).

$7^{a}$ parada - Museu de Ciências da Terra (MCTer): a performance foi realizada na escadaria externa do MCTer (Figura 10) e teve como objetivo evidenciar os aspectos geológicos e arquitetônicos da sua fachada. Para este local foi selecionada a apresentação do poema "Passando em frente", de Eucanaã Ferraz, realizada por Júlia Mayer e Mallu Oliveira, introduzindo a história do imponente prédio: "Passando em frente / ao antigo, imponente prédio / o leão, velho, para / e repara, atento / naquele seu estranho parente / Repara nas patas / bem postas / pesadas, afiadas / nos pelos, nos olhos / em tudo que, granítico / jamais apodrece. / O leão velho vê / a si mesmo / e inveja o irmão de pedra / Pensa, por exemplo, que / não poderia 
guardar / entradas de edifícios / como faz o pétreo / leão de guarda / impávido, perfeito. / Enquanto medita, moscas / fazem festa em volta de sua juba / um tanto suja / Não há como negar, e / todo ele, desse jeito, mostra / uma ternura engraçada. / O leão de pedra / ao contrário, é / depois de um século, todo empáfia / um rei / que não morre / que permanece, e / mais rei por isso. / O leão de pedra, imóvel / guarda a entrada do templo / enquanto o outro / procura por nós, igual / a nós, dentro do tempo." A construção do MCTer é revestida e ornamentada em gnaisse facoidal, evidenciando que a rocha, além de ser uma das mais abundantes nos morros cariocas, também está presente em diversas construções históricas da cidade. $O$ MCTer possui em sua fachada principal esculturas que fazem alusão a dois momentos políticos distintos do país, os leões representando a Monarquia e as águias, a República (TOSATTO, 1997). O prédio é um dos mais famosos da Urca, sendo muito utilizado para a tomada de fotografias pelo seu apelo estético. Sua história se confunde com a história do bairro, mas apesar de toda esta importância científica, didática, histórica e cultural poucos turistas ou cariocas visitam o local, pela restrita divulgação das suas exposições (que são gratuitas), tendo apenas uma pequena placa na entrada do prédio informando que o local é um museu.

A história e a beleza da fachada não são os únicos atrativos do MCTer, que conta também com uma grande coleção, além de exposições. A reserva técnica do MCTer é a mais importante coleção de Geologia e Paleontologia (representando o Patrimônio Paleontológico ex situ brasileiro), possuindo o maior acervo fossilífero do país, de grande relevância do ponto de vista científico e didático. Os fósseis são subdivididos em cinco tipologias: peixes, répteis, mamíferos, invertebrados e paleobotânica. Este material é constituído por exemplares coletados em diversas expedições do corpo técnico em suas atividades de campo e por doações, com exemplares oriundos de todo o Brasil e do exterior. Além de fósseis, o acervo também é constituído por coleções de minerais, meteoritos, rochas e documentos únicos, relacionados à memória das Geociências, estando parte em exposição. As exposições de longa duração do MCTer são "No Tempo dos Dinossauros", "O que é Geofísica?", "Mostra Mineralógica e Petrográfica", e "LLewellyn Ivor Price + 100, um Paleontólogo". Sua biblioteca contém em torno de 90 mil volumes de publicações relacionadas às Geociências. Criado sob a chefia do geólogo americano Orville Derby (1851-1915), o museu é reconhecido como um marco na história patrimonial e cultural, principalmente na história das Geociências no Brasil. O início de sua história data da criação do Serviço Geológico e Mineralógico do Brasil - SGMB, em 10/01/1907, pelo Decreto no 6.323. O mesmo Decreto cria a Repartição, um Laboratório e o Museu de Geologia e Mineralogia. Atualmente encontra-se fechado, em reforma.

Esta última parada teve como objetivo evidenciar a presença de elementos da geodiversidade em construções históricas cariocas, mostrando assim que a Geologia está diretamente associada com a evolução urbana da cidade. No caso da Urca, em específico, essa relação fica evidente na localização estratégica dos equipamentos militares de defesa e na utilização das rochas para a estruturação e revestimento dos edifícios históricos, além da construção de aterros que permitiram a ocupação em si de grande parte do bairro. 


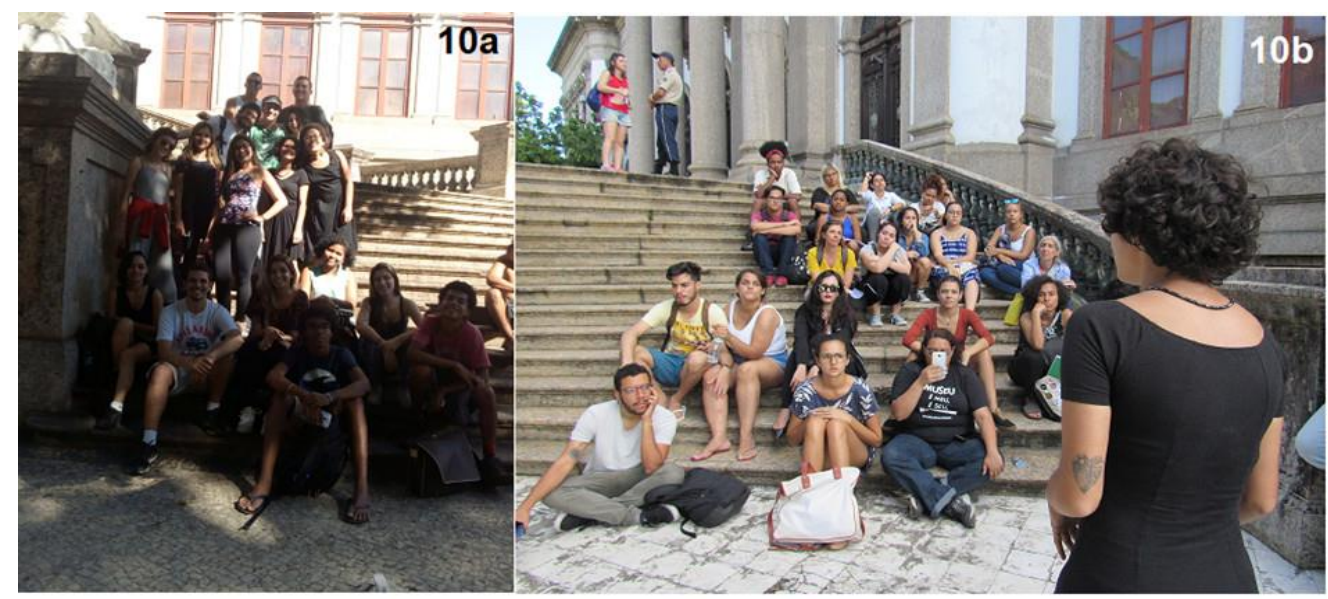

Figura 10: (a) Escadaria do Museu de Ciências da Terra - MCTer, após o encerramento do roteiro;

(b) Performance do poema "Passando em frente" por Julia Mayer, em frente ao MCTer. Fonte: (a) foto de Luiza Ponciano (2018); (b) foto de Mallu Oliveira, (2018).

Figure 10: (a) Staircase of the Museum of Earth Sciences - MCTer, after the end of the tour;

(b) Performance of the poem "Passando em frente" by Julia Mayer in front of the MCTer.

Source: (a) photo by Luiza Ponciano (2018); (b) photo by Mallu Oliveira (2018).

Os participantes dos roteiros avaliaram a atividade por meio de questionários que foram enviados posteriormente por e-mail, apontando as performances do GeoTales como um dos principais pontos positivos, tendo sido sugerido ampliar a realização das performances para todas as paradas do roteiro. O total de participantes atingidos pelos dois roteiros realizados foi de 50 pessoas. Desse total, nove pessoas foram estudantes do Pré-Vestibular Popular da Engenharia da UFF, que participaram no dia 24 de junho de 2018, e 41 pessoas foram discentes do curso de Museologia da UNIRIO (no dia 29 de novembro de 2018). Os dados de avaliação utilizados aqui são referentes às respostas do dia 29 de novembro, sendo que apenas 20 pessoas responderam ao questionário, pois não era uma atividade obrigatória. A maior parte (90\%) afirmou que foi possível compreender os conteúdos das Geociências apresentados durante a atividade, e todos afirmaram que foi possível perceber as relações entre geodiversidade, história, cultura e urbanização da cidade por meio dos pontos selecionados para o roteiro. Sobre a duração da atividade, isso foi abordado em duas perguntas: (1) "O número de pontos selecionados foi adequado?" e (2) "O tempo de duração do roteiro foi adequado?". Para a primeira pergunta, $80 \%$ dos participantes responderam positivamente. A tendência se confirmou na segunda pergunta, onde $75 \%$ dos participantes responderam que o tempo foi adequado. Quando questionados sobre os pontos positivos das atividades, foi destacada a importância da integração dos temas e das abordagens ao longo das paradas do roteiro, sendo elogiada a combinação entre as informações selecionadas para serem transmitidas em cada ponto e os poemas e performances apresentadas pelo GeoTales, que proporcionaram uma maior fluidez para atividade e uma ampliação nas possibilidades de percepção da paisagem.

\section{Considerações finais}

Os roteiros geoturísticos são uma importante ferramenta para a popularização das Geociências. No Rio de Janeiro, a maioria dos locais mais famosos possui uma forte relação entre os seus atrativos turísticos e o Patrimônio Geológico da cidade. Somam-se a estas características a grande concentração populacional, a maior 
infraestrutura de transportes e serviços e a diversidade de manifestações culturais que se reúnem nas metrópoles, configurando o Rio de Janeiro um local excelente para a realização do Geoturismo Urbano.

O bairro da Urca tem destaque neste potencial geoturístico da cidade do Rio de Janeiro, pois os seus pontos turísticos mais famosos, os morros do Pão de Açúcar e da Urca, foram formados por processos geológicos que ocorreram há milhões de anos e são amplamente estudados por diversos segmentos das Geociências, apesar de ainda serem pouco conhecidos pela população. Esses morros também são amplamente retratados em diversas histórias, poemas e outras expressões artísticas que fazem parte da cultura carioca, tendo sido muito relevante a integração das Artes na elaboração deste novo roteiro geoturístico que envolve a Geopoética e a Geomitologia. A união dos conteúdos geocientíficos com história e a cultura do bairro por meio do roteiro demonstrou ser uma excelente maneira de divulgar o Patrimônio Geológico da cidade.

Ressalta-se também a importância deste roteiro, que tem o seu diferencial na conexão com as Artes, para o fortalecimento da relação de afeto entre os citadinos e o seu Patrimônio Natural tanto in situ quanto ex situ, pois como já dizia Adélia Prado, "O transe poético é o experimento de uma realidade anterior a você. Ela te observa e te ama. Isto é sagrado. (...) É seu próprio olhar pondo nas coisas uma claridade inefável". O despertar destas relações afetivas das pessoas com o ambiente é essencial para estimular as práticas de Geoconservação, que também devem ser realizadas nas cidades.

\section{Referências}

ABREU, M. A. A evolução urbana do Rio de Janeiro. Rio de Janeiro: Instituto Pereira Passos, 2013. $147 \mathrm{p}$.

ARAÚJO, C. V. F. Ecoturismo, sua prática, seu espaço. 2003. 95 p. Dissertação (Mestrado em Geografia) - Instituto de Geociências, Universidade Federal Fluminense, Niterói, 2003.

ARAUJO, J. M.; PEIXINHO, F. L.; PONCIANO, L. C. M. O. Maracajá e a Pedra da Onça: geomitologia na cidade do Rio de Janeiro. Anais do II Colóquio de Zoologia Cultural, 2., Rio de Janeiro, Revista A Bruxa, n. especial, 2017.

ARAUJO, J. M.; PONCIANO, L.C.M.O. O Gigante adormecido da Baía de Guanabara: divulgando a Geomitologia associada ao Pão de Açúcar. Anais do III Colóquio de Zoologia Cultural, 3., Revista A Bruxa, n. especial, p.124-125, 2018.

BRASIL. Ministério do Meio Ambiente. SNUC - Sistema Nacional de Unidades de Conservação da Natureza: Lei no 9.985, de 18 de julho de 2000; Decreto no 4.340, de 22 de agosto de 2002; Decreto n 5.746, de 5 de abril de 2006. Plano Estratégico Nacional de Áreas Protegidas: Decreto no 5.758, de 13 de abril de 2006. Brasília: Ministério do Meio Ambiente, 2011. 76 p.

CAPREZ, P. Por uma Geopoética Urbana (Arte, Cidade e Paisagem). Geograficidade [Online], v. 7, n. 2, p. 49-60, 2017.

DESFILE COMPLETO CARNAVAL 2014 - Portela. 2014. (1h19m28s). Disponível em: <https://www.youtube.com/watch?v=sW6ODvZcdzw>. Acesso em: 05 fev. 2019. 
DIAS, A. G. O Gigante de Pedra. In: Últimos cantos, 1851. Disponível em: $<$ http://www.avozdapoesia.com.br/obras ler.php?poeta id=225\&obra id=13685 > . Acesso em: 06 jun. 2018.

DUARTE, J. R. A. Marco de posse e fundação da cidade do Rio de Janeiro. Disponível em: <http://www.riodejaneiroaqui.com/portugues/marco-da-cidade.html>. Acesso em: 25 jan. 2019.

FERREIRA, L. F.; COUTINHO, M. C. B. Ecoturismo: visitar para conservar e desenvolver a Amazônia. Brasília: Ministério do Meio Ambiente, 2002. 52 p.

GRAY, M. Geodiversity: valuing and conserving abiotic nature. London, England: John Wiley and Sons, 2004. $315 \mathrm{p}$.

HOSE, T. A. European geotourism: geological interpretation and geoconservation promotion for tourists. In: BARRENTINO, D.; WINBLEDON, P.; GALLEGO, E. (eds.). Geological Heritage: its conservation and management, Madrid, Spain, 2000. p. 127-146.

HOSE, T. A. Selling the story of Britain's stone. Environmental Interpretation, v. 10, n. 2, p. 16-17, 1995.

IPHAN. Corcovado e Complexo do Pão de Açúcar (RJ) comemoram 42 anos de tombamento. 2015.2 Disponível em: $<$ http://portal.jphan.gov.br/ri/noticias/detalhes/3185/ corcovado-e-complexo-do-paode-acucar-ri-comemoram-42-anos-de-tombamento>. Acesso em: 05 fev. 2019.

IPHAN. Morro Cara de Cão (Rio de Janeiro, RJ). 1973. Disponível em: $<$ http://portal.iphan.gov.br/ans.net/tema consulta. $a s p$ ?Linha=tc arque.gif\&Cod=1756 >. Acesso em: 05 fev. 2019.

JOHNNIE WALKER | NEOGAMA BBH. 2013. (1m03s). Disponível em: $<$ https://youtu.be/jSrehs9jipU>. Acesso em: 05 fev. 2019.

KORYTOWSKI, I. Fortaleza de São João (Urca). 2009. Disponível em: $<$ http://literaturaeriodejaneiro.blogspot.com/2009/05/fortaleza-de-sao-joao-urca.html> Acesso em: 27 fev. 2019

KOZEL, S. Geopoética das paisagens: olhar, sentir e ouvir a "Natureza". Caderno de Geografia, v. 22, n.37, p. 65-78, 2012.

LICCARDO, A.; MANTESSO-NETO, V.; PIEKARZ, G. F. Geoturismo urbano: educação e cultura. Anuário do Instituto de Geociências [Online], v. 35-1, p. 133141, 2012.

LINDBERG, K.; HAWKINS, D. E. Ecoturismo: um guia para planejamento e gestão. São Paulo: SENAC São Paulo, 1995. 278p.

LIRA, M. Migalhas Folclóricas. Rio de Janeiro: Gráfica Lammert, 1951. p. 56-57.

MANSUR, K. L. Projetos educacionais para a popularização das geociências e para a geoconservação. Revista do Instituto de Geociências, São Paulo: USP, v. 5, p. 63-74, 2009. Publicação especial.

MANSUR, K. L. Guia geoturístico para a trilha Cláudio Coutinho e arredores, cidade do Rio de Janeiro, RJ. Anais do Encontro Nacional de Educação em Geociências para o Ensino Básico, 1., 2015, Rio de Janeiro, 2015. Guia da Excursão no Monumento Pão de Açúcar, 2015. 
MANSUR, K. L.; CARVALHO, I. S.; DELPHIM, C. F. M.; BARROSO, E. V. O gnaisse facoidal: a mais carioca das rochas. Anuário do Instituto de Geociências - UFRJ, Rio de Janeiro, v. 31, n. 2, p. 9-22, 2008b.

MANSUR, K.L.; CARVALHO, I.S.; DELPHIM, C.F.M BARROSO, E.V. O gnaisse facoidal e a cidade do Rio de Janeiro: um caso clássico de paisagem cultural, 2008a. Memórias e Notícias. Publicação do Departamento de Ciências da Terra e do Museu Mineralógico e Geológico da Universidade de Coimbra, n. 3, p. 469-473. [online]. Disponível em: <https://www.researchgate.net/publication/236165206>. Acesso em: 23 jan. 2019

MELO, M. A. 2013. No dia do índio: a história do gigante adormecido. Blog Educar para Transformar. Disponível em: <http://trasnformandovidas.blogspot.com.br/ 2013/04/no-dia-do-indio-história-do-gigante.html>. Acesso em: 4 abr. 2018.

MENÉNDEZ, I. G. Experimentar-se Natureza - Uma proposta de práticas para o encontro. 2018. 134 p. Dissertação (Mestrado em Ecoturismo e Conservação) Centro de Ciências Biológicas e da Saúde (CCBS), Universidade Federal do Estado do Rio de Janeiro, Rio de Janeiro, 2018.

MOREIRA, J. C. Geoturismo e interpretação ambiental [online]. 1. ed. Ponta Grossa: Editora UEPG, 2014. 157 p.

MOREIRA, J. C. Interpretação ambiental, aspectos geológicos e geomorfológicos. Boletim Geográfico, Maringá, v. 30, n. 2, p. 87-98, 2012.

MOREIRA, J. C. Patrimônio geológico em unidades de conservação: atividades interpretativas, educativas e geoturísticas. 2008. 374p. Tese (Doutorado em Geografia) - Centro de Filosofia e Ciências Humanas, Universidade Federal de Santa Catarina, Florianópolis, 2008.

MOTTA, M. Sobre Rochas: Rio de Janeiro. Rio de Janeiro: Andrea Jakobsson, 2017. $251 \mathrm{p}$.

NASCIMENTO, M. A. L; RUCHKYS, U. A.; MANTESSO-NETO, V. Geodiversidade, Geoconservação e Geoturismo: trinômio importante para a proteção do patrimônio geológico. [São Paulo]: Sociedade Brasileira de Geologia, 2008. p. 82.

NEIMAN, Z.; MENDONÇA, R. Ecoturismo: discurso, realidade e desejo. Turismo em Análise, São Paulo, v. 11, n. 2, p. 98-110, 2000.

NEWSOME, D.; DOWLING, R. The scope and nature of Geoturism. In: NEWSOME, D.; DOWLING, R. Geoturism: sustainability, impacts and management. [S.I.]: Elsevier, 2006. p. 3-26.

NIKLAS, J. Palco do Cassino da Urca é revitalizado para receber visitantes. O Globo Rio, matéria online de 24 de novembro de 2017. [online] Disponível em: $<$ https://oglobo.globo.com/rio/palco-do-cassino-da-urca-revitalizado-para-recebervisitantes-22107424>. Acesso em: 05 fev. 2019.

PEREIRA. R. G. F. A. Geoconservação e desenvolvimento sustentável na Chapada Diamantina (Bahia - Brasil). 2010. Tese (Doutorado em Ciências) - Escola de Ciências, Universidade do Minho, Portugal, 2010. p. 295.

PIPER, W. S. The Eagle of Thunder Cape. New York: The Knickerbocker Press. 1924. 156p. 
PONCIANO, L. C. M. O. Geomitologia: era uma vez... na história da Terra. Revista Sentidos da Cultura, Belém, ano 2, n. 2, p. 22-42, jan.-jun., 2015.

PONCIANO, L.C.M.O. 2018. Geotales: narrando as histórias petrificadas pela Terra. Revista Sentidos da Cultura, Belém, n.5, p.34 - 48, dez., 2018.

PONCIANO, L. C. M. O.; CASTRO, A. R. S. F.; MACHADO, D. M. C.; FONSECA, V. M. M.; KUNZLER, J. Patrimônio geológico-paleontológico in situ e ex situ: definições, vantagens, desvantagens e estratégias de conservação. In: CARVALHO, I. S. et al. (org.). Paleontologia: Cenários de Vida. Rio de Janeiro: Editora Interciência, 2011. v. 4, p. 853-870.

PRATES, T. A. A Escola Naval. Revista de Villergagnon - Revista Acadêmica da

Escola Naval, ano V, n. 5, 2010. [online] Disponível em: <https://www.marinha. mil.br/en/revista villegagnon>. Acesso em: 27 jan. 2019

RÊGO, G. S. M. M.; FERNANDES, J. L. J. A topofilia dos cidadãos para com o patrimônio natural urbano: o caso da cidade de Coimbra. Geotextos, v. 8, n. 1, p. 11-32, 2012.

RIO DE JANEIRO. DECRETO MUNICIPAL № 26.578, DE 1ํㅡㄹ JUNHO DE 2006. Disponível em: <http://www.rio.ri.gov.br/dlstatic/10112/4462114/4112614/Atode Criacao MONA.pdf>. Acesso 23 fev. 2019.

RIO DE JANEIRO. Plano de Manejo do MONA dos Morros do Pão de Açúcar e da Urca: Caracterização da UC. Rio de Janeiro: Secretaria Municipal de Meio Ambiente, 2011. p. 395. Disponível em: <http://www.rio.ri.gov.br/web/smac/ exibeconteudo?id=4461307> Acesso em: 25 fev. 2019.

RIO DE JANEIRO. Guia das Áreas de Proteção do Ambiente Cultural (APACs): Urca. Rio de Janeiro: Instituto Rio Patrimônio da Humanidade, 2012. p. 16.

RUCHKYS, U. Patrimônio geológico e geoconservação no Quadrilátero Ferrífero, Minas Gerais: potencial para a criação de um Geoparque da UNESCO. 2007. Tese (Doutorado em Geologia) - Instituto de Geociências, Universidade Federal de Minas Gerais, Belo Horizonte, 2007. p. 211.

SANTOS, L.B.M.; PONCIANO, L.C.M.O.; SILVA, P.J.A.S.; MAÇÃO, G.B.; PIMENTEL, I.B.S.; MELO, D.B.; PEIXINHO, L.F.; ARAUJO, J.M.; LEME, G.F.P. GeoTales: divulgação das Geociências atravessada pela poética das vozes da Terra. In: PONTES, H.S.; MOCHIUTTI, N.F.B.; MASSUQUETO, L.L.; GUIMARÃES, G. B.. (Org.). Anais... Simpósio Brasileiro de Patrimônio Geológico, 4.; Encontro Luso-Brasileiro De Patrimônio Geomorfológico E Geoconservação, 2. 1. ed. Ponta Grossa: UEPG, v. 1, p. 16-20, 2017.

SANTOS, M. A Natureza do espaço: técnica e tempo, razão e emoção. 4. ed., 2. reimpr. São Paulo: EdUSP, 2006. p. 259.

SILVA, L. C.; CUNHA, H. C. S. Geologia do Estado do Rio de Janeiro. Brasília: Companhia de Pesquisas em Recursos Minerais, 2001. 94 p.

SOUZA, A. F. A Bahia do Rio de Janeiro: Sua história e descrição de suas riquezas. Rio de Janeiro, 1882. 340 p. Disponível em: <http://www2.senado. leg.br/bdsf/item/id/174429 >. Acesso em: 06 jun. 2018.

TILDEN, F. Interpreting our Heritage. 3. ed. Chapel Hill: The University Of North Carolina Press, 1977. 119 p. 
TUAN, Y. Topofilia: um estudo da percepção, atitudes e valores do meio ambiente. São Paulo: Difel, 1980. 288 p.

TOSATTO, P. Um palácio na histórica geológica brasileira. 2. ed. Brasília: Departamento Nacional de Produção Mineral, 1997. 124 p.

UCEDA, A. C. El Patrimonio Geologico: ideas para suprotección, conservación y utilización. In: MOPTMA -MIN. OBR. PÚBL. TRANP. MED. AMB. El patrimônio geológico. Bases para suvaloración, protección,conservación y utilización. Madrid, 1996. p. 17-27.

Organização das Nações Unidas para a Educação, a Ciência e a Cultura (UNESCO). Rio de Janeiro recebe da UNESCO certificado de Patrimônio Mundial pela sua Paisagem Cultural. 2016. Disponível em:<www.unesco.org/new/pt/brasilia/about-this-office/single-view/news/rio de janeiro receives from unesco the certificate of world/> Acesso em: 25 fev. 2019.

VALERIANO, C. M.; HEILBRON, M.; ALMEIDA, J. C. H. Precambrian gneisses in Rio from the Sugar Loaf to the Arpoador outcrops - Field Trip Guide. In: Congresso Internacional de Geologia, Rio de Janeiro, 2000.18 p.

VALERIANO, C. M. 2006. A odisséia do Pão de Açúcar: as rochas contam sua história... Projeto Caminhos Geológicos. DRM-RJ. Disponível em: <http://www.drm.ri.gov.br>. Acesso em: 27 dez. 2018

VALERIANO, C. M.; HEILBRON, M.; NASCIMENTO, V.; MANSUR, K. L. 2007a. A Geologia do morro do Corcovado. Projeto Caminhos Geológicos. DRM-RJ. Disponível em:<http://www.drm.ri.gov.br>. Acesso em: 12 dez. 2018

VALERIANO, C. M.; HEILBRON, M.; NASCIMENTO, V.; MANSUR, K. L. 2007b. De braços abertos para a Geologia. Projeto Caminhos Geológicos. DRM-RJ. Disponível em:<http://www.drm.ri.gov.br>. Acesso em: 27 dez. 2018

VALERIANO, C. M.; MAGALHÃES, A. C. Geologia estrutural da área do Pão de Açúcar e adjacências, Rio de Janeiro, Brasil. Anais da Academia Brasileira de Ciências, Rio de Janeiro, p. 295-303, 1984.

VALERIANO, C. M; SILVA, L. C. (Org.). Geologia e recursos minerais da folha Baía de Guanabara SF-23-Z-B-IV, Estado do Rio de Janeiro, escala 1:100.000. 1. ed. Belo Horizonte: Companhia de Pesquisas em Recursos Minerais, 2012, v. 1, p. 156.

WEARING, S.; NEIL, J. Ecoturismo: impactos, potencialidades e possibilidades. [São Paulo]: Manole, 2001. 256 p.

\section{Agradecimentos}

A toda equipe do Programa de Pós-graduação em Ecoturismo e Conservação (PPGEC - Mestrado profissional, UNIRIO), onde a pesquisa "Patrimônio Geológico e a paisagem da cidade do Rio de Janeiro: atrativos para a realização do Geoturismo Urbano" está sendo desenvolvida, do Laboratório de Tafonomia e Paleoecologia Aplicadas (LABTAPHO) e do GeoTales, que sempre auxiliam nas performances associadas com o projeto, especialmente às integrantes citadas no texto, que participaram das atividades relacionadas acima. 
Bernardo Perrota Legal Gomes: Universidade Federal do Estado do Rio de Janeiro, Rio de Janeiro, RJ, Brasil

E-mail: bernardoperrota@id.uff.br

Link para o currículo Lattes: http://lattes.cnpq.br/980109486286218

Kátia Leite Mansur: Universidade Federal do Rio de Janeiro, Rio de Janeiro, RJ, Brasil

E-mail: katia@geologia.ufrj.br

Link para o currículo Lattes: http://lattes.cnpq.br/2321793386300188

Luiza Corral Martins de Oliveira Ponciano: Universidade Federal do Estado do Rio de Janeiro, Rio de Janeiro, RJ, Brasil

E-mail: luiza.ponciano@unirio.com

Link para o currículo Lattes: http://lattes.cnpq.br/0519721250469036

Data de submissão: 28 de fevereiro de 2019

Data de recebimento de correções: 21 de agosto de 2019

Data do aceite: 21 de agosto de 2019

Avaliado anonimamente 